NASA/TM-2005-213828

\title{
Rotating Rake Turbofan Duct Mode Measurement System
}

Daniel L. Sutliff

Glenn Research Center, Cleveland, Ohio 
Since its founding, NASA has been dedicated to the advancement of aeronautics and space science. The NASA Scientific and Technical Information (STI) Program Office plays a key part in helping NASA maintain this important role.

The NASA STI Program Office is operated by Langley Research Center, the Lead Center for NASA's scientific and technical information. The NASA STI Program Office provides access to the NASA STI Database, the largest collection of aeronautical and space science STI in the world. The Program Office is also NASA's institutional mechanism for disseminating the results of its research and development activities. These results are published by NASA in the NASA STI Report Series, which includes the following report types:

- $\quad$ TECHNICAL PUBLICATION. Reports of completed research or a major significant phase of research that present the results of NASA programs and include extensive data or theoretical analysis. Includes compilations of significant scientific and technical data and information deemed to be of continuing reference value. NASA's counterpart of peerreviewed formal professional papers but has less stringent limitations on manuscript length and extent of graphic presentations.

- TECHNICAL MEMORANDUM. Scientific and technical findings that are preliminary or of specialized interest, e.g., quick release reports, working papers, and bibliographies that contain minimal annotation. Does not contain extensive analysis.

- CONTRACTOR REPORT. Scientific and technical findings by NASA-sponsored contractors and grantees.
- CONFERENCE PUBLICATION. Collected papers from scientific and technical conferences, symposia, seminars, or other meetings sponsored or cosponsored by NASA.

- SPECIAL PUBLICATION. Scientific, technical, or historical information from NASA programs, projects, and missions, often concerned with subjects having substantial public interest.

- TECHNICAL TRANSLATION. Englishlanguage translations of foreign scientific and technical material pertinent to NASA's mission.

Specialized services that complement the STI Program Office's diverse offerings include creating custom thesauri, building customized databases, organizing and publishing research results ... even providing videos.

For more information about the NASA STI Program Office, see the following:

- Access the NASA STI Program Home Page at http://www.sti.nasa.gov

- E-mail your question via the Internet to help@sti.nasa.gov

- Fax your question to the NASA Access Help Desk at 301-621-0134

- Telephone the NASA Access Help Desk at 301-621-0390

- Write to:

NASA Access Help Desk

NASA Center for AeroSpace Information 7121 Standard Drive

Hanover, MD 21076 
NASA/TM-2005-213828

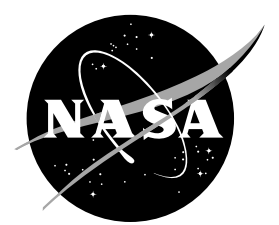

\section{Rotating Rake Turbofan Duct Mode Measurement System}

Daniel L. Sutliff

Glenn Research Center, Cleveland, Ohio

Prepared for

NOISE-CON 2005

sponsored by the Institute of Noise Control Engineering

Minneapolis, Minnesota, October 17-19, 2005

National Aeronautics and

Space Administration

Glenn Research Center 


\section{Acknowledgments}

The concept of inducing a Doppler shift to separate the circumferential modes was first put forth by Tom Sofrin while at Pratt and Whitney. The first implementation of the continuously rotating rake was at NASA Glenn by a team led by Larry Heidelberg. Kevin Konno was the primary mechanical system designer. Dave Hall developed the original data acquisition and processing routines. The Rotating Rake won the NASA Glenn Steven V. Szabo Award for Excellence in Engineering in 2004.

Trade names or manufacturers' names are used in this report for identification only. This usage does not constitute an official endorsement, either expressed or implied, by the National Aeronautics and Space Administration.

Available from

NASA Center for Aerospace Information 7121 Standard Drive

Hanover, MD 21076
National Technical Information Service 5285 Port Royal Road Springfield, VA 22100 


\title{
Rotating Rake Turbofan Duct Mode Measurement System
}

\author{
Daniel L. Sutliff \\ National Aeronautics and Space Administration \\ Glenn Research Center \\ Cleveland, Ohio 44135
}

\begin{abstract}
An experimental measurement system was developed and implemented by the NASA Glenn Research Center in the 1990 s to measure turbofan duct acoustic modes. The system is a continuously rotating radial microphone rake that is inserted into the duct. This Rotating Rake provides a complete map of the acoustic duct modes present in a ducted fan and has been used on a variety of test articles: from a low-speed, concept test rig, to a full-scale production turbofan engine. The Rotating Rake has been critical in developing and evaluating a number of noise reduction concepts as well as providing experimental databases for verification of several aero-acoustic codes. More detailed derivation of the unique Rotating Rake equations are presented in the appendix.
\end{abstract}

\section{Symbols}

$\begin{array}{ll}\text { a,b } & \text { constants } \\ \text { A } & \text { duct area } \\ \text { B } & \text { number of fan blades } \\ \text { C } & \text { normalizing coefficient } \\ \text { D } & \text { duct diameter } \\ \text { E } & \text { duct profile function } \\ \text { f } & \text { frequency } \\ \text { h } & \text { fan fundamental harmonic } \\ \text { J } & \text { Bessel function - 1st kind } \\ \text { k } & \text { wave number } \\ \text { M } & \text { Mach number } \\ \text { m } & \text { circumferential mode order } \\ \text { N } & \text { number of pulses per fan rev } \\ \mathrm{n} & \text { radial mode order } \\ \text { p } & \text { acoustic pressure } \\ \text { P } & \text { modal pressure amplitude } \\ \hat{P} & \text { modal power amplitude } \\ \text { Q } & \text { weighting function } \\ \text { R } & \text { duct radius } \\ \text { r } & \text { radial co-ordinate } \\ \text { t } & \text { temporal co-ordinate } \\ \text { S } & \text { fan shaft harmonic } \\ \text { V } & \text { number of vanes } \\ \text { X } & \text { axial co-ordinate } \\ \text { Y } & \text { Bessel function - 2nd kind } \\ & \end{array}$

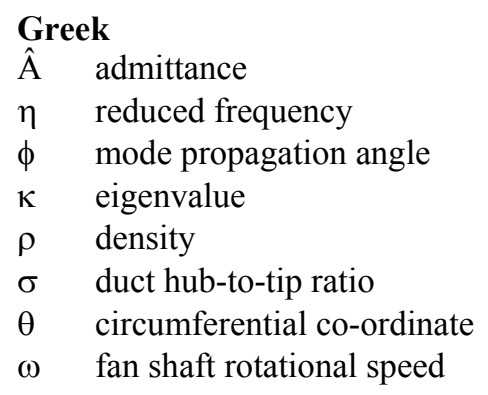


$\Omega \quad$ rake rotational speed

$\checkmark \quad$ fan/rake speed ratio

$\checkmark$ acoustic particle velocity

$\zeta \quad$ cut-off ratio

$\mathrm{Z}$ Impedance

\section{Introduction}

The NASA Glenn and Langley Research Centers have been involved in several programs (Advanced Subsonic Technology - AST, Quiet Aircraft Technology - QAT) whose goals were the reduction in transport aircraft noise attributed to the engine. A component of engine noise is fan tone noise caused by rotor-stator, and other interaction, coupled to duct propagation. Interaction modes contribute to the farfield tone noise generated by turbofan engines (ref. 1). In order to reduce tone noise it is desirable to understand the generation of these interaction modes. Detailed knowledge of the modal structure may indicate engine modifications that can quiet the overall tone signature. It is difficult to determine the modal content solely from farfield directivity. Analytical modal description (refs. 2 and 3 ) of turbofan noise is well understood. Previous methods to experimentally measure duct modes used a concentric rake face or a reposition-able radial rake. These methods had drawbacks in that they either contaminated the acoustic field with their wakes or required lengthy, discontinuous data acquisition.

In order to develop fan tone noise reduction techniques, a diagnostic tool was needed to measure the interaction modes of ducted fans. A concept for a continuously rotating microphone rake (refs. 4 and 5) was put forth that would be able to obtain all modal amplitudes in a reasonable data acquisition time. The key concept of the Rotating Rake is that by slowly rotating in a manner locked to the fan shaft, a Doppler shift is imparted to the duct spinning modes that is uniquely based on the mode physics. The resulting Rotating Rake system developed by the NASA Glenn Research Center has made several advances in the understanding of turbofan mode generation. In addition to directly evaluating a noise reduction technique, this diagnostic tool can provide an experimental database to which the results of aero-acoustic prediction or propagation codes can be benchmarked. This paper describes the theory and implementation of the Rotating Rake with historical examples. An appendix to the full paper, published as a NASA TM, provides derivation of equations unique to the Rotating Rake.

\section{Duct Mode Theory}

First, a summary of the duct mode theory with an application to mode propagation and generation is presented in order to understand the noise signature being measured.

\section{Cylindrical Wave Equation}

The propagation of sound in a circular duct with uniform flow is governed by the convective wave equation. In cylindrical co-ordinates this equation is written in non-dimensional form as:

$$
\nabla^{2} p(r, \Theta, x, t)=\left(\frac{\partial}{\partial t}+M \frac{\partial}{\partial x}\right)^{2} p(r, \Theta, x, t)
$$

with a general solution of

$$
P(\theta, r, x, t)=p_{m n f} * E_{m n}\left(k_{m n} r\right) e^{i\left(2 \pi f t+m \theta \pm k_{m n} x\right)}
$$

where

$$
E_{m n}\left(\kappa_{m n} r\right)=C_{m n}\left[J_{m}\left(\kappa_{m n} r\right)+Q_{m n} Y_{m}\left(\kappa_{m n} r\right)\right]
$$

is a solution to Bessel's equation. The index $m$ is defined as the circumferential order defining the number of pressure cycles in the circumferential direction. The index $n$ defines the radial order, the number of pressure nodes in the radial direction. The nature of the radial rake indicates that of primary interest is the radial solution. 
The constant, $C_{m n}$, is a weighting factor that normalizes the arbitrary Bessel function profile to a desired physical property. (As an aside the selection of $C_{m n}$ will affect the calculated mode pressure amplitude but the mode power level will be a fixed value regardless of the choice.) The normalizing physical property chosen for Rotating Rake analysis due to a desire to compare results to a predictive tool is (ref. 6):

$$
\int_{\text {area }} p^{2} d A \equiv A \quad \text { which results in: } \begin{aligned}
\frac{1}{C_{m n}^{2}}= & \frac{1}{2}\left\{\left[1-\frac{m^{2}}{\kappa_{m n}^{2}}\right]\left[J_{m}\left(\kappa_{m n}\right)+Q_{m n} Y_{m}\left(\kappa_{m n}\right)\right]^{2}\right. \\
& \left.-\left[\sigma^{2}-\frac{m^{2}}{\kappa_{m n}^{2}}\right]\left[J_{m}\left(\kappa_{m n} \sigma\right)+Q_{m n} Y_{m}\left(\kappa_{m n} \sigma\right)\right]^{2}\right\}
\end{aligned}
$$

For selected physical cases (hardwall condition or no-flow) this result arises from the principle of orthogonality. For the general case, the E-functions based on the eigenvalue solution are not orthogonal. However the above identity for $C_{m n}$ is also used for convenience in these cases.

The eigenvalues are determined from the boundary conditions; in the standard case it is the hardwall condition that the acoustic pressure be normal to the duct inner and outer wall (a consequence of zero acoustic velocity at the wall).

$$
\left.\frac{d P}{d r}\right|_{\sigma} ^{1}=0 ; E_{m n}^{\prime}\left(\kappa_{m n} 1\right)=E_{m n}^{\prime}\left(\kappa_{m n} \sigma\right)=0
$$

The case with a duct with passive treatment (softwall) where

$$
\begin{gathered}
\frac{p}{v}=\frac{Z}{\rho c} ; \hat{A}=\frac{\rho c}{Z} ; \eta=\frac{\omega R}{c} \\
\text { outer wall }: \kappa_{m n} \frac{E_{m-1, n}\left(\kappa_{m n}\right)}{E_{m n}\left(\kappa_{m n}\right)}-m=-i \eta \hat{A}_{o w}\left(1-M \frac{k_{m n}}{\eta}\right)^{2} ; \\
\text { inner wall }: \kappa_{m n} \frac{E_{m-1, n}\left(\kappa_{m n} \sigma\right)}{E_{m n}\left(\kappa_{m n} \sigma\right)}-\frac{m}{\sigma}=i \eta \hat{A}_{i w}\left(1-M \frac{k_{m n}}{\eta}\right)^{2}
\end{gathered}
$$

Note that while we are focusing on the radial solution, it is coupled to the circumferential and axial solutions through the mode order $m$ and the eigenvalue $\kappa_{m n}$.

The above boundary conditions show that real eigenvalues occur in the hardwall case and complex eigenvalues result from the softwall case; this is a concept that propagates throughout the analysis. The eigenvalues are determined from the boundary conditions. It is convenient to normalize the radial co-ordinate by the duct wall outer radius and define the hub-to-tip ratio as the inner wall radius normalized by the duct radius. Also, as convention the 1 st eigenvalue is called the zero radial, designated by $n=0$. This allows for a short physical definition of a mode as the number of zero crossings of the pressure profile. The mode $m=0, n=0$, is uniform in pressure across the duct and is defined as the plane wave. Figure 1 shows a graphical representation of these modes with the regions of light/dark representing positive/negative acoustic pressure. Mathematically, an infinite number of radial modes (eigenvalue solutions) for each circumferential mode (also an infinite set) exist. 


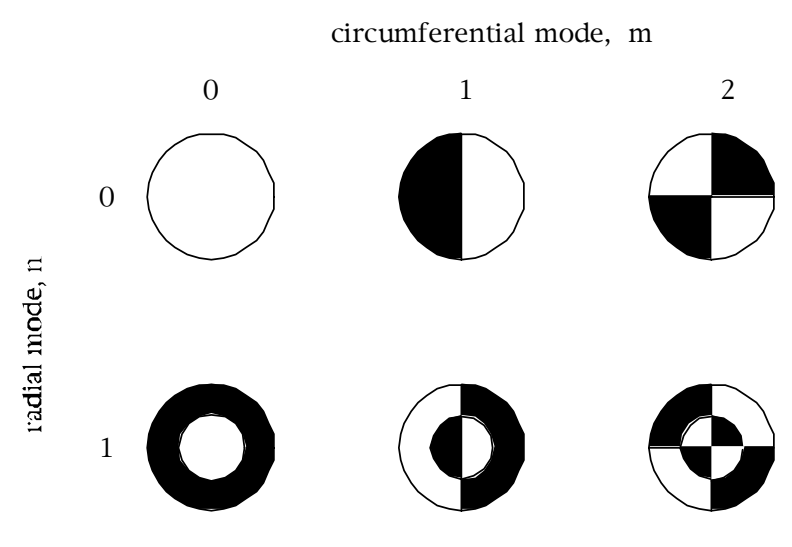

Figure 1.-Duct mode graphical representation. (a)

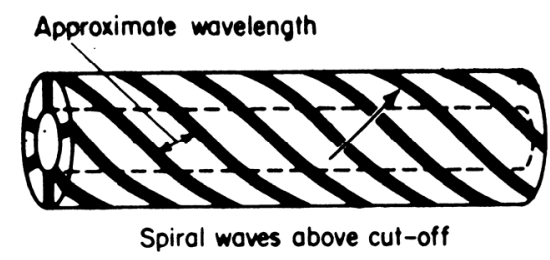

Spiral woves above cut-off

(b)

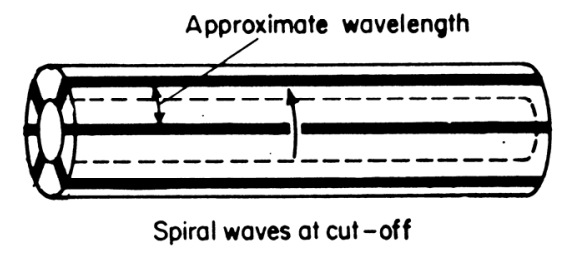

Figure 2.-Wave propagation in cylindrical duct.

\section{Propagation}

Although an infinite number of solutions exist, physical conditions allow only for a fixed subset of modes to propagate. The separated solution in the $\mathrm{x}$-direction was given as:

$k=\frac{\eta}{1-M^{2}}\left[-M \pm \sqrt{1-\left(1-M^{2}\right)\left(\frac{\kappa}{\eta}\right)^{2}} ; \quad \eta=\frac{2 \pi f R}{c} \quad\right.$ for $\quad M=0 \rightarrow k= \pm \sqrt{\left(\frac{2 \pi f R}{c}\right)^{2}-\beta^{2} \kappa^{2}} ; \quad \beta=\sqrt{\left(1-M^{2}\right)}$

The axial wave number is $k_{m n}$. Examination of this equation gives three possible solutions:

$$
\begin{aligned}
& \text { i) } 2 \pi f R / c>\beta \kappa_{m n} ; \quad k_{m n}=a \quad \rightarrow \quad e^{i k x}=e^{i a x} \quad \Rightarrow \text { cyclic propgation in } x \text {-direction } \\
& \text { ii) } 2 \pi f R / c=\beta \kappa_{m n} ; \quad k_{m n}=0 \\
& \text { iii) } 2 \pi f R / c<\beta \kappa_{m n} ; \quad k_{m n}=i b \rightarrow e^{i k x}=e^{i(i b) x}=e^{-b x} \Rightarrow \text { exponential decay in } x \text {-direction }
\end{aligned}
$$

A real term when incorporated into the exponential term results in cyclical variation in the combined term. Thus a real wave number results in propagation in the $\mathrm{x}$-direction. An imaginary wave number results in a pure real in the exponent, resulting in exponential decay. The special case of $k_{m n}=0$ defines the cut-off frequency. Physically, the $3 \mathrm{D}$ waves have a helix propagation angle. Highly cut-on modes approximate a plane wave. Cut-on modes have an axial wavelength that is longer than would occur in free space at that frequency (shorter wave-number). Cut-off modes have 'infinite' axial wavelength (zero wave-number - decay). Figure 2 illustrates this propagation. The propagation angle (Ref. 7) is given by:

$$
\cos (\phi)=\frac{-M \pm \sqrt{1-\frac{1}{\zeta^{2}}}}{1 \mp M \sqrt{1-\frac{1}{\zeta^{2}}}} ;= \pm \sqrt{1-\frac{1}{\zeta^{2}}} \text { for } M=0 ; \text { where } \zeta=\frac{2 \pi f R}{\kappa_{m n} c \sqrt{1-M^{2}}} ; \quad=2 \pi f R / \kappa_{m n} c \quad \text { for } M=0
$$

It is worth repeating the concept that a given $(m, n)$ mode will propagate only if the frequency is above the cut-off frequency. For frequencies only somewhat below cut-off, it can be shown that a $50 \mathrm{~dB}$ attenuation per duct diameter occurs. The eigenvalue, $\kappa_{m n}$, increases with $m$ or $n$, that is, the cut-off frequency increases with higher modes. This results in a sequential cut-on of modes from low order to high order as the frequency (or RPM) increases. For a given duct, the modes that propagate are from 0 to $m_{\max }$; the highest number of radial modes, from $n=0$ to $n=n_{\max },(0,0)$ to $\left(0, n_{\max }\right)$ will propagate at $m=0$; each successive circumferential order will have fewer radial modes until at $m_{\max }$ only the first radial mode will propagate $\left(m_{\max }, 0\right)$. 


\section{Rotor-Stator Interaction}

The number of possible modes, while reduced from infinity, can still be substantial. A typical high-speed fan (shown later) may have up to $50 \mathrm{~m}$-orders with up to 12 radial modes resulting in 600 modes. Fortunately, the number of modes that need to be considered is a subset of these propagate-able modes.

The classic paper by Tyler and Sofrin (ref. 8) presents the theory of fan-duct mode generation and propagation. This is seen by the kinematics between the rotor and stator. Figure 3 illustrates the progression of the pulse (which can be extrapolated to a continuous, cyclic profile). An illustrative rotor with $\mathrm{B}=8$, and $\mathrm{V}=6$ stators demonstrates that an interaction between a select rotor blade and stator vane progresses in the circumferential direction as the rotor turns. This pulse can be seen to travel in one complete revolution when the rotor has turned only $1 / 4$ revolution.

The rotor locked mode $(k=0, m=B)$ spins at the shaft rotation speed. This mode, and higher order modes, can only propagate in a narrow annular duct if the blade tip speed corresponding to its spin rate is above Mach $=1.0$. Lower order modes, which spin faster, may propagate if their spin rate results in a sonic blade tip speed. The critical tip Mach number is greater than 1.0 for non-narrow annular ducts. Sofrin demonstrated that generation of, and the spin rate of, circumferential spinning modes is governed by the following equations:

$$
\text { generation: } \quad m=s B \pm k V ; \quad \text { spin rate: } \quad \Omega_{m}=s B \Omega / m
$$

Each circumferential mode, $m$, can have one or more radial modes, $n$. Mode propagation is dependent on the cut-off frequency, which is unique to each $(m, n)$ mode. This frequency is dependent on geometric parameters and the eigenvalue of a combined Bessel function that is a solution to the cylindrical wave equation. Below the cut-off frequency the mode will decay exponentially. Above cut-off propagation occurs and acoustic power is transmitted down the duct and into the farfield. The Bessel function eigenvalue incorporates the duct geometry effects. The cut-off frequency, and cut-off ratio with Mach number effects is given by (ref. 9):

$$
f_{\text {cut }-o f f}=\frac{c \kappa_{m n}}{\pi D} \quad \zeta=\frac{\pi f D}{R \sqrt{\left(1-M^{2}\right) \cos (2 \phi)}} ; \quad k=R e^{i \phi}
$$

The cut-off ratio reduces to the familiar form when the eigenvalue is real (hardwall). The cut-off ratio rewritten in traditional turbomachinery form gives the ratio of the mode frequency to its cut-off frequency (for $M=0$,

hardwall case):

$$
\zeta=\frac{\pi s B \Omega D}{60 \kappa_{m n} c}=\frac{s B(\Omega / 60)}{f_{\text {cut }-o f f}}
$$
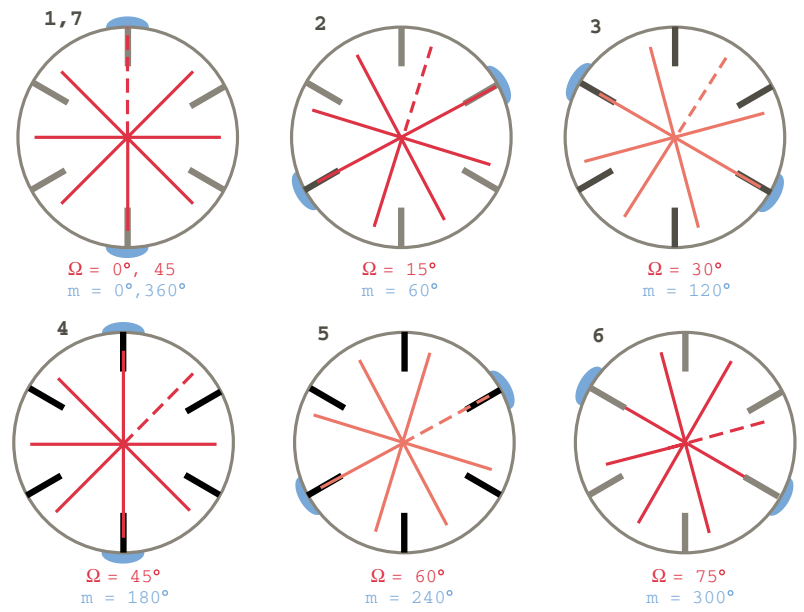

Figure 3.-Interaction of rotating pressure pulse stationary object. 


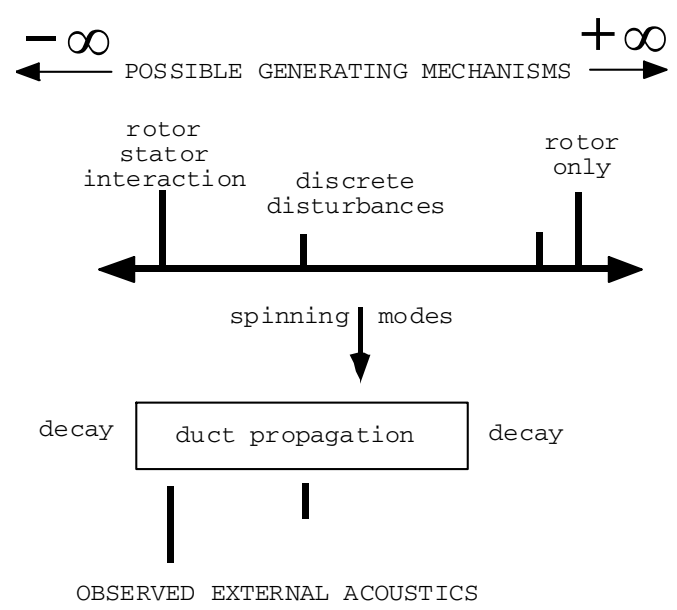

Figure 4.-Duct mode generation and with propagation constraints.

The primary method of generation of these spinning modes is the periodic interaction of the rotor wake impinging on the stator vanes as described. The stator vanes primary purpose is recovery of the rotational energy generated from the rotor (swirl). Other primary sources are inlet or exhaust duct struts, installed for structural support. These are typically the primary modes of interest in turbomachinery. Secondary methods of generation are caused by a change in rotor blade loading due to aerodynamic disturbances upstream of the rotor. If these disturbances are periodic with respect to the rotor, spinning modes may be generated. Discontinuities in the duct wall can generate unwanted modes. These modes, while generally undesirable, can contain significant acoustic levels. A summary of the preceding sections is given in figure 4.

\section{Rotating Rake Implementation}

\section{Operating Principle}

The underlying principle of the Rotating Rake is the concept from the previous section that every circumferential mode spins at a different, discrete rate. The rake, rotating slowly, imparts a Doppler shift on the fan fundamental that is unique to each circumferential mode. This frequency separation is a linear function of the mode number and the rake rotation speed; the higher the mode number the greater the frequency shift with $m=0$ un-shifted (remaining at the harmonic frequency). This relationship, (derivation shown in the appendix) is:

$$
\text { let } \frac{\Omega}{\omega}=\frac{1}{v}, \quad \text { freq } \rightarrow=\omega\left(B-\frac{m}{v}\right)
$$

Figure 5 shows a spectrum from a single microphone with the rake stationary, compared to a spectrum for the same microphone with the rake rotating. The separation of the modes about the fundamental shaft order 16 is clearly seen. Cut-on background modes are $20 \mathrm{~dB}$ above the cut-off modes. The dominant rotor-stator interaction is $15 \mathrm{~dB}$ above these extraneous modes. 


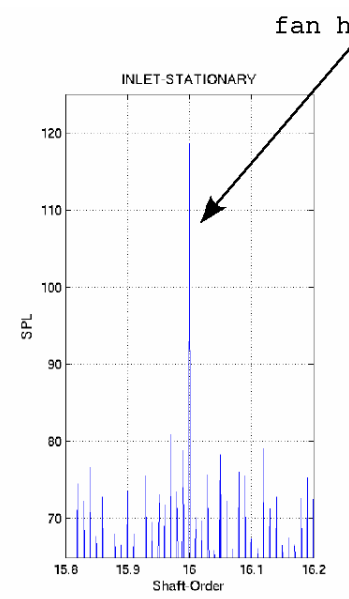

Ean harmonic

Figure 5.- Illustration of spectral Doppler shift due to rake rotation.

\section{Implementation}

The rake acquires unsteady pressure data as it spins using a series of radially distributed microphones or pressure transducers pointing at the fan. The rake is used in two locations - the inlet and the exhaust. The inlet rake rotates around the duct centerline inside the nacelle at the throat. At the nozzle, the rake rotates at the exit plane of the bypass duct. The rotational speed of the rake was required to be a specific whole number fraction, and in phase with the shaft. This means that when the fan has rotated $v$ times, the Rotating Rake will have completed exactly one revolution within $\pm 0.2^{\circ}$. The speed ratio, $v$, has been from 100 to 250 . This speed and phase synchronization is necessary in order to resolve the Doppler induced frequency shift of the spinning acoustic modes. Consequently, the rake requires a very accurate drive and control system. This accuracy must also be repeated over the entire test period (5 to $10 \mathrm{~min}$.) without build-up of phase error. The rake must follow the fan precisely even though the fan will wander in speed ( 5 to $10 \mathrm{rpm}$ or so) throughout the test period. Consequently, the rake drive system must be slaved directly to the fan.

The general method used for this precise following requirement is a programmable closed loop stepper or servo motor drive system. Both have been used in previous Rotating Rake applications. Commercial programmable motor control/drive systems are well suited for this type of application, easily meeting the design requirements if carefully selected. The rake motor drive system is an internal closed loop drive utilizing a programmed step/direction controller output driving a brushless servo or stepper motor; externally the motor drive system is an open loop system. The fan velocity is determined from a multi-per-rev physical sensor mounted on the shaft. A once-per-rev signal sets the fan position. Variations of this sensor have been an indexer mounted on the shaft, a gear tooth pick-up, or a blade-proximity sensor. The higher the number of signals per revolution, the better the rake system can track fan speed changes smoothly. This signal is fed into the manufacturer's software for the motor control. A timing signal from the rake rotational body is used solely for position verification by monitoring on an oscilloscope. If the rake speed sensor resolution (pulses-per-rev) is equal to the speed ratio $v$, then when the rake is synchronized, the traces of the fan-one-per-rev and the rake $v$-per-rev will line up exactly, with no drift in time. Finally a rake body one-per-rev signal is used to provide information on the rake absolute position, which is important for determining absolute mode phase.

The transducers' time history signals must be brought across the rotating boundary. The method used is to bring the conditioned signal across by VHF/UHF telemetry. Again, carefully selected commercial units with custom design modifications have been found to be adequate to these requirements. The signal conditioning and telemetry transmitters must be mounted in the Rotating Rake drive housing. Power to supply these electronics can either be supplied by batteries in the rotating platform, or brought across by rails. The telemetry receivers must be diversity (two channels per frequency) type as the rotation will cause dropouts in the signal that must be picked up by a second channel. It has been found that close mounting of the antenna pairs is required.

The output of the telemetry receivers is fed into a high-speed multi-channel data acquisition system. A primary requirement of the data acquisition system is the ability to synchronously sample the analog signal using the fan multi-per-rev signal, $N$. For analysis purposes, the ideal choice for $N$ is $8 B$. This is because typically the 3rd harmonic $(3 B)$ is the highest 'frequency' typically analyzed. To satisfy the Nyquist criteria, a sampling rate more 
than twice that must be used. Further, since FFTs are more efficient when using a power-of-2, $8 B$ fits nicely. The signal must be synchronously acquired to the external fan shaft signal due to the time domain averaging employed to separate the tone signals from the broadband and flow noise. Think of the whole system as a strobe light. If the strobe light is set to a fixed (internal) rate, the rotating object may appear to drift. Connecting the strobe light to a timing signal causes the rotating object to 'freeze'. Experience has shown that if any one of these synchronizing components is in error (drift, sample drop-out, noise) the data will be invalid. Best wiring practices are essential.

Other requirements of the data system are the ability to record and store long continuous time histories ( $\sim 5 \mathrm{~min}$.) without breaking the trace into records. This requirement arises from the 25 continuous rake revolutions required to obtain good separation of the tones from broadband and flow noise. Ideally, each channel must have 'zero' relative phase shift, or this must be accounted for in the post-processing.

Finally, the number of transducers chosen must be greater than the highest number of radial modes that will be anticipated, usually the number of radial modes predicted to be cut-on at the $m=0$ at the 3rd harmonic. A uniform radial distribution of the transducers along the rake has been chosen based upon experience.

\section{Rake Effects}

An obvious concern when taking inlet measurements would be the extraneous noise caused by the ingestion of the rake-wake contaminating the results. Indeed a stationary rake $(V=1)$ would generate every mode. However, in the reference frame of the rake, the rotation of the rake-wake and the relative speeds of the fan/rake cause all of the modes generated by the rake-wake rotor interaction to occur only at a single mode, that of the $m=n B$ (fig. 5). This is also the so-called rotor mode that is cut-off below sonic tip speed. Therefore, the rake-wake interference is outside the typical modal analysis range unless the rotor tip speed is sonic. Conceptually, in the reference frame of the rake, it is as if the rake is stationary and the fan rotates at $(\Omega-\omega)$ so that the rake-wake modes appear at that frequency. The mathematical verification of this intuitive observation is shown in the appendix.

Both rakes have windscreens covering the transducers. The oscillating vortex shedding from the inlet rake body occurs at the measurement frequency of interest under certain conditions. A porous aluminum foam windscreen was attached along the trailing edge of the inlet rake covering the microphones to eliminate the vortex shedding noise from the rake body (the transducers are on the trailing edge of the rake) as seen in figure 6 . In the exhaust duct, the rotor wake potential field convects downstream with a circumferential variation in a manner similar to acoustic modes. This can severely contaminate the microphone signals resulting in poor data. A tri-shield arrangement for the exhaust rake to lower interaction with the viscous wake was developed based on the concept that the convection is at the duct Mach number rather than the speed of sound resulting in a steeper propagation angle. The data quality was greatly improved with the addition of the shields as shown in figure 7 for a typical microphone. The convected wake levels at the non-propagating modes $(m=-12,+16)$ is nearly eliminated, and the contamination of the propagating mode $m=+2$ propagating mode is reduced. The resulting significant improvement in the radial profile is shown in figure 8. Finally, in the exhaust, the rake blockage must be taken into account. Typically for a high-pressure rise fan the nozzle area must be increased to account for this in order to make mode comparisons on a relevant basis.

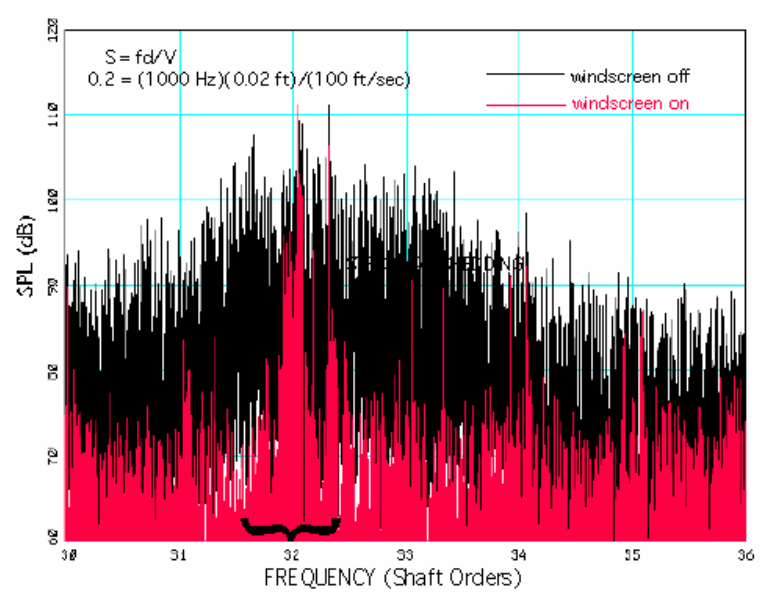

Figure 6.- Reduction of strouhal-shedding due to installation of inlet rake shield.

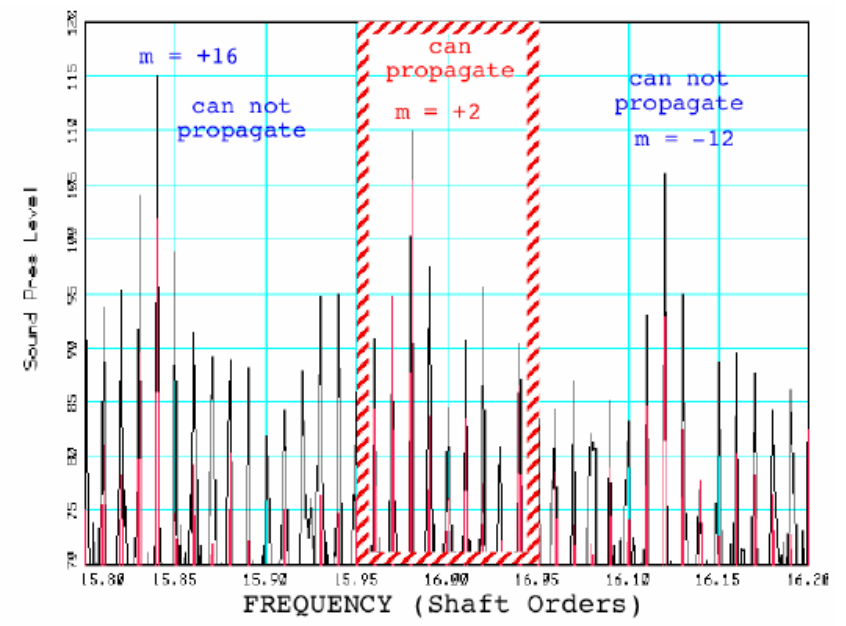

Figure 7.-Reduction of wake contamination due to installation of exhaust rake shields. 


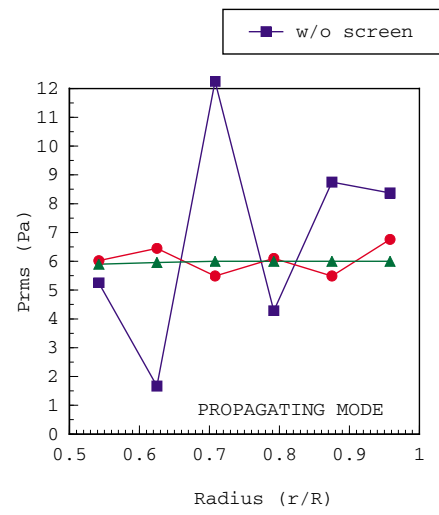

- w screen $\rightarrow$ computed

Figure 8.-Improvement in radial profile due to installation of exhaust rake shields.

\section{Data Reduction and Analysis}

The pressure time histories are acquired and recorded for each transducer as well as the timing signals through the data acquisition system described earlier. Experience has determined that 25 rake revolutions of data are required to obtain good signal-to-noise levels in the processed data. This time history is then time domain averaged (TDA) by taking record lengths 10 rake revolutions long and offsetting the next block by 1 rake revolution. This will typically result in 15 averages. Also this block length yields 10 bins in between modes when computing the FFT. The FFT of these TDA blocks are then reduced into complex magnitude for each Doppler shifted circumferential mode at each microphone radial location. A practical limit chosen for the modal decomposition is $m= \pm 3 B$, about each harmonic. The modal pressures are computed from the least-squares-fit of the radial Bessel functions to the actual pressure profile. A vector error is determined at each radial location from the difference between the actual and computed complex pressures divided by the maximum experimental pressure. The overall error of the solution is defined as the average of the radial mode vector errors. The discrete form of the pressure in the duct for a given frequency, m-order, at a specific radial location is:

$$
p_{f, m, r}=\sum_{n=0}^{\infty} p_{f, m, n} E_{m n}\left(\kappa_{m n} r\right) ; \quad \text { and in matrix form: } \quad\left[P_{r}\right]=\left[E_{v r}\right]\left[P_{n}\right]
$$

applying least-squares analysis, inverting and solving for the modal amplitudes:

$$
\left[P_{n}\right]=\left[F_{v n}\right]^{-1}\left[E_{v r}\right]\left[P_{r}\right]
$$

where

$$
\left[F_{v n}\right]=\left[\begin{array}{ccc}
\sum_{i=1}^{N_{p}} E_{m 0}^{2}\left(\kappa_{m 0} r_{i}\right) & \ldots & \sum_{i=1}^{N_{p}} E_{m 0}\left(\kappa_{m 0} r_{i}\right) E_{m N_{\max }}\left(\kappa_{m N_{\max }} r_{i}\right) \\
\vdots & & \vdots \\
\sum_{i=1}^{N_{p}} E_{m N_{\max }}\left(\kappa_{m N_{\max }} r_{i}\right) E_{m 0}\left(\kappa_{m 0} r_{i}\right) & \ldots & \sum_{i=1}^{N_{p}} E_{m N_{\max }}^{2}\left(\kappa_{m m N_{\max }} r_{i}\right)
\end{array}\right] ; \quad\left[E_{v r}\right]=\left[\begin{array}{ccc}
E_{m 0}\left(\kappa_{m 0} r_{1}\right) & \ldots & E_{m 0}\left(\kappa_{m 0} r_{N p}\right) \\
\vdots & & \vdots \\
E_{m N_{\max }}\left(\kappa_{m N_{\max }} r_{1}\right) & \ldots & \left.E_{m N_{\max }\left(\kappa_{m N_{\max }} r_{N p}\right)}\right)
\end{array}\right]
$$

$P_{r}$ is the vector measured pressures at a the microphone location and the solution vector, $P_{n}$, is the modal coefficients; both complex. The size of the matrix is dependent on the number of microphones, and the highest radial mode being analyzed. Based on experience the numerical solution requires the curve fit to $N_{\max }+1$ radial modes for a hardwall solution. For a softwall solution the decay rate must be taken into consideration and may require a larger matrix. 
Mode power is an important parameter in duct acoustics and provides a better description of the acoustic field, compared to mode pressure, especially when relating to the external acoustics. Power rather than pressure is the physical parameter that is conserved. Many wall modal techniques are unable to calculate modal power. The definition of power, and the final form of the computation used is:

$$
\text { Power } \rightarrow \hat{\mathrm{P}}=\int_{A}\left\langle I_{x}\right\rangle d A ; \quad I_{x}=\left(\frac{p}{\rho_{0}}+U u\right)\left(\rho_{0} u+\rho U\right) ; \Rightarrow \hat{\mathrm{P}}=\mp \frac{\pi R^{2}\left(1-\sigma^{2}\right)}{\rho_{0} c_{0}}|\beta|^{4} R E\left\{\frac{\sqrt{1-\frac{1}{\zeta^{2}}}}{\left|1 \pm M \sqrt{1-\frac{1}{\zeta^{2}}}\right|^{2}}\right\} \mid P^{2}
$$

This form mathematically illustrates the effect of cut-off ratio. For the hardwall case the cut-off ratio was shown to be a pure real number. If the cut-off ratio is greater than one, then the term in braces is also a real number, hence non-zero power. If the cut-off ratio is less than one, the numerator becomes a pure imaginary number due to the square root and power is identically zero. For the softwall, case the cut-off ratio is a complex number and non-zero power exists regardless of the cut-off ratio magnitude (power is the real component of the term in the braces).

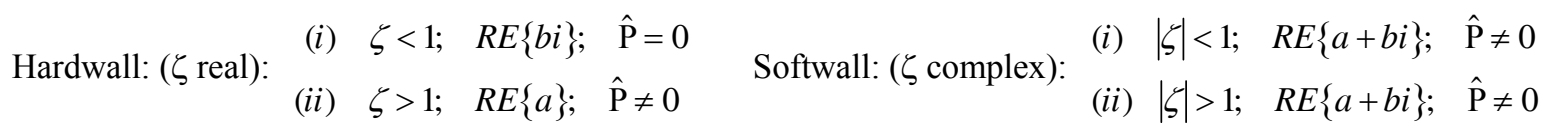

Other parameters calculated from the decomposed modal data that are presented are the pressure levels of the inner wall and outer wall. $\mathrm{C}_{\mathrm{mn}}$ is a the normalizing coefficient discussed earlier. The function multiplier is the coefficient of the un-normalized Bessel function. The Sofrin coefficient is defined as the maximum pressure along a radial profile. The Power Level (PWL) is calculated, including cut-off ratio and Mach number effects, and summed to obtain the total mode power level. Table I shows typical output from the standard data reduction. All circumferential modes are analyzed in this manner and typically plotted in a 3-D 'tombstone' plot shown in figure 9. The base plane axes are $m$ - and $n$-order, and the vertical value axis is the PWL in the $(m, n)$ mode. Along the wall of the $m$-order axis, the sum of all the radial modes provides the power in that circumferential mode. The sum of all the modes provides the PWL in the harmonic presented. A typical modal decomposition provides information as to the dominant modes present, usually those from the rotor stator interaction. Of secondary interest will be other modes, which may be due to inflow distortions or other geometric disturbances. Phase information, while tabulated is generally not plotted.

\section{TABLE I.-TYPICAL DATA OUTPUT}

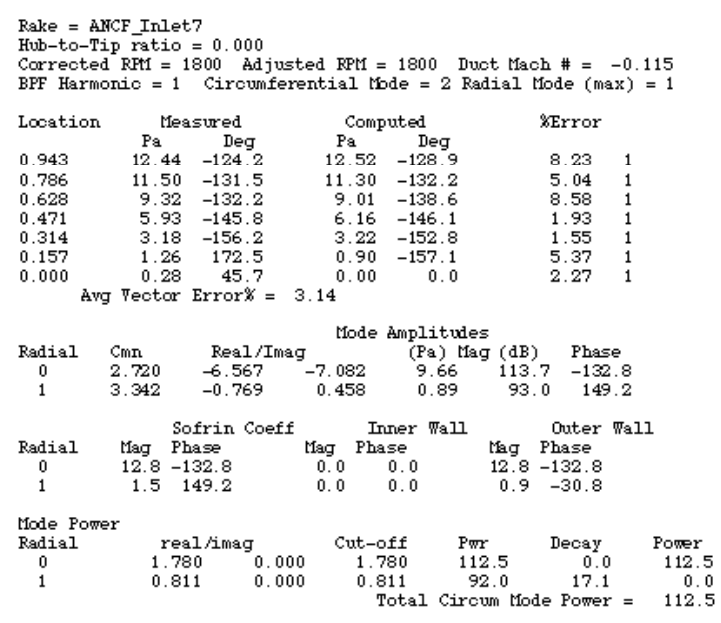

NASA/TM-2005-213828

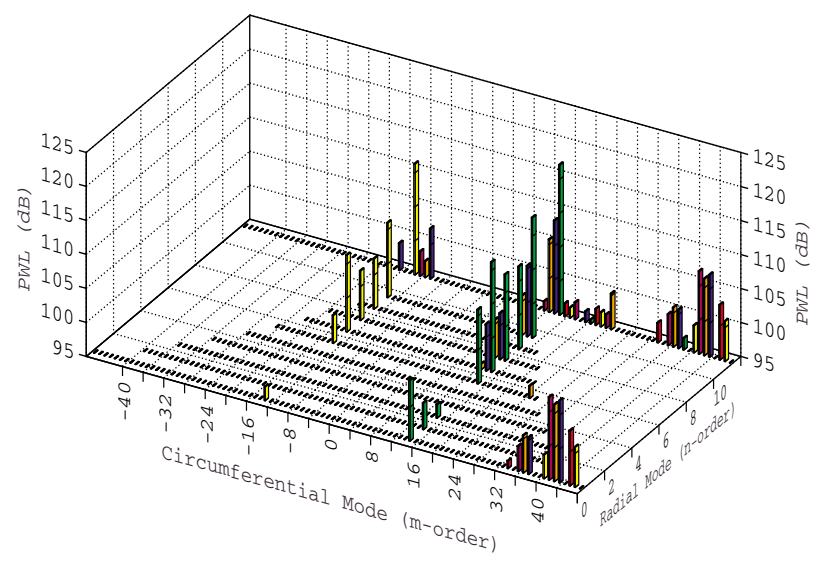

Figure 9.-3-D plot of all mode amplitudes. 


\section{Achievements}

Several Rotating Rake systems have been custom built for three facilities. In order of complexity of the turbomachinery test article, these are (1) the Advanced Noise Control Fan, (2) various high speed scale model fan rigs in the NASA Glenn 9- by 15-foot wind tunnel, and (3) a full scale turbofan, the Honeywell TFE731-60.

\section{Advanced Noise Control Fan}

The Advanced Noise Control Fan (refs. 10 and 11) (ANCF) was designed in the early 90s and first checkouts occurred in 1996. This unique fan was designed as a test bed for evaluating noise reduction technologies, code verification/development, and to continually improve the Rotating Rake system. The ANCF is a 4-ft diameter ducted fan (fig. 10) with several unique features. The cantilever nature of the rotor support structure allows for the rotor alone to be run, eliminating the need for support struts. The 16-bladed rotor, in conjunction with variable count- and position stator vane sets, allows for a wide combination of modes to be generated.

The ANCF has separate rotating rake systems in the inlet and exhaust ducts to allow for quick though not simultaneous measurements. The rotating rakes on the ANCF rotate at $1 / 100$ th of the nominal fan shaft speed of $1800 \mathrm{rpm}$ (i.e., $18 \mathrm{rpm}$ ) and contain 7 (inlet) or 6 (exhaust) microphones. A drive motor connected to a straight shaft and gear assembly is coupled to a ring gear. This ring gear is embedded into an Aluminum housing which forms part of the duct contour. These rake assemblies can be located between any of the discrete duct sections to allow measurements to be taken at several points along the duct axis. This has been extremely useful in validating propagation codes. Though the primary measurement system is the rotating rake, the ANCF has other aeroacoustic measurement systems (surface pressures, hot film, farfield) that allow for determination of the relationship of duct modes to the physics.

The ANCF played a fundamental role in the NASA Advanced Subsonic Technology Active Noise Control (ANC) program. The evaluation of the modal effects of a tested ANC system provided by the rotating rake was crucial to understanding and improving the ANC algorithms. Several advances in the understanding of mode generation (ref. 12), propagation (ref. 13), and radiation (ref. 14) and verification of codes resulted from tests run on the ANCF. Other mode measurement systems (ref. 15) were verified on the ANCF providing confidence in those systems to be used in more demanding environments. The Hershel-Quinke (ref. 16) noise reduction concept was evaluated on the ANCF. These tests led to modifications of the H-Q devices for full-scale turbofan tests. A recent promising concept for fan noise reduction, wake filling through the use of trailing edge blowing (ref. 17) was evaluated on the ANCF and vetted for a more complex test on a high-speed fan. Advanced trailing edge blowing concepts are being currently investigated in the high-speed fan regime.
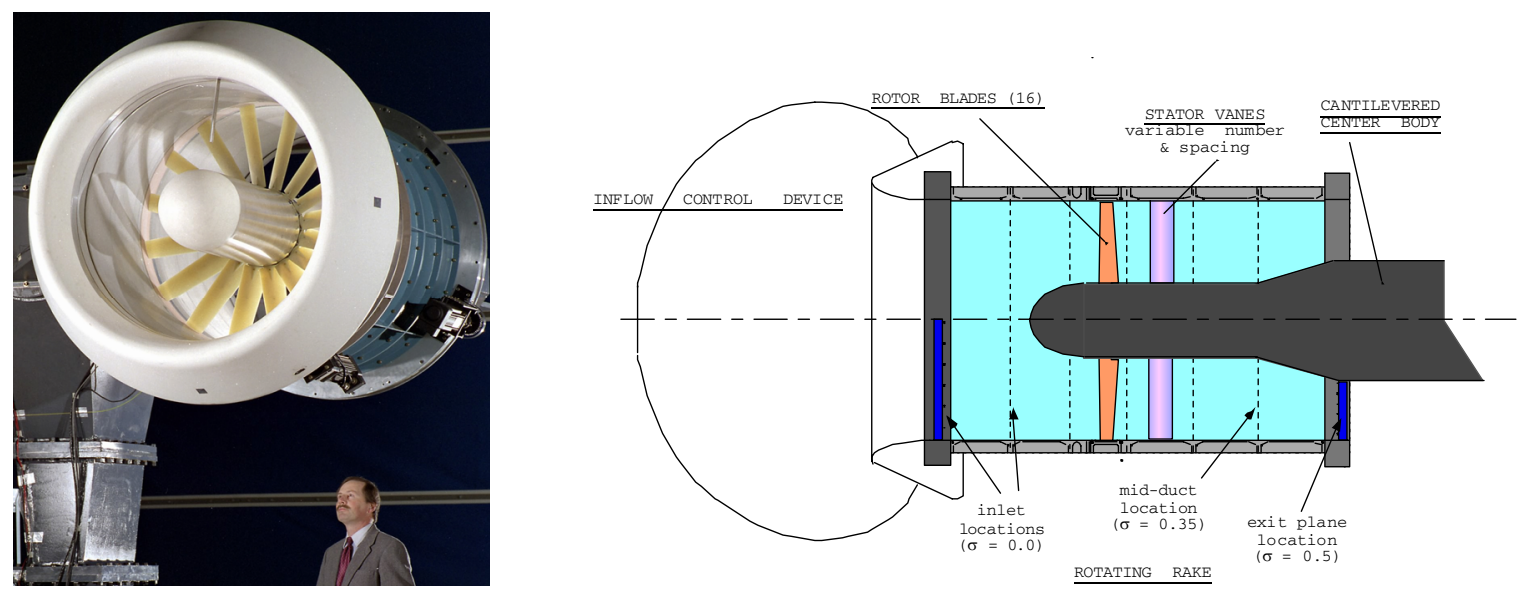

Figure 10.- Rotating rakes on advanced noise control fan. 


\section{Twenty-Two-Inch Fan Drive Rig}

The 22 in. fan rig in the NASA Glenn 9- by 15-foot Anechoic Wind Tunnel is an air-turbine driven rig that can have a specifically designed fan installed and tested. Typically a test program will involve detailed performance and acoustic evaluations. The test section Mach number is generally held at 0.2 .

The first application of the rotating rake system (ref. 18) was in 1991 for the Advanced Ducted Propulser (ADP) fan model that was designed and built to test fan noise. This fan was an 18-bladed rotor $17.25 \mathrm{in}$. in diameter. The rake motor drive was connected to a large ring gear to which the rake body was mounted. The rake body/ring gear assembly rotated at $1 / 250$ th of the fan speed $(12,000 \mathrm{rpm})$ or $48 \mathrm{rpm}$. This assembly was fastened to the tunnel floor and ceiling via a support arm. The complete fan and rake assembly is shown in figure 11 .

Configurations tested were a cut-on stator vane set (22 vanes) as well as a traditional cut-off set (40 vanes). Three inlet lengths were tested $\left(\mathrm{L} / \mathrm{D}_{\mathrm{f}}=0.21,0.41\right.$, and 0.53$)$. This test documented experimentally for the first time the effects of mode cut-on. A weak tendency for lower mode levels with shorter inlet length was noted. Also, it was discovered that very minor perturbations in the rotor casing treatment cause extraneous modes, resulting in higher acoustic farfield levels. This cause would have been difficult to identify from the farfield data.

The next iteration of rotating rake mechanical design for the 22 in. fan rig was a conformal design to provide better mechanical stability and flow characteristics, and to allow for more flexible positioning of the measurement plane. The rake assembly was housed in a drum system that was mounted on parallel rails. The rake drum housing can be slid to various axial positions to accommodate different measurement planes; including all the way aft to enable exhaust duct mode measurements. The more robust structural mounting allowed for a faster rotational speed, $1 / 200$ th of the fan. These features can be seen in figure 12.

This system was used on the ADP in 1996. The purpose of the test (ref. 19) was to evaluate the potential for fan noise reduction by lowering fan tip speed. Acoustic modes were measured for two fans of equal pressure ratio. Fan 2 had a tip speed 90 percent of Fan 1 depending on condition. Initial assumptions were that the lower tip speed fan would be quieter, but the mode measurements did not support this assumption. One complicating factor was that in order to maintain the performance Fan 2 required 51 stator vanes compared to Fan 1's 45. The different interaction modes generated ( $m=-9$ vs. $m=-15)$ at 2 BPF may make comparisons difficult as the ANCF has shown that some interaction modes couple better to the duct. This test was the first to document the assumption that co-rotating modes (negative $m$ orders) do not propagate well through the rotor. This transmission loss has a significant impact on inlet noise.

The Active Noise Control program culminated in the test of a hybrid passive/active system (ref. 20) for tone reduction in a high-speed fan. The measurements made by the Rotating Rake were key to the design of the system. The baseline, passive only, active only, and hybrid active/passive systems were tested. The mode measurements showed significant reductions were achieved using the active control system, as well as a possible 'synergistic' benefit in that the reduction achieved by the combined system was greater than the sum of the reduction achieved by the systems individually.

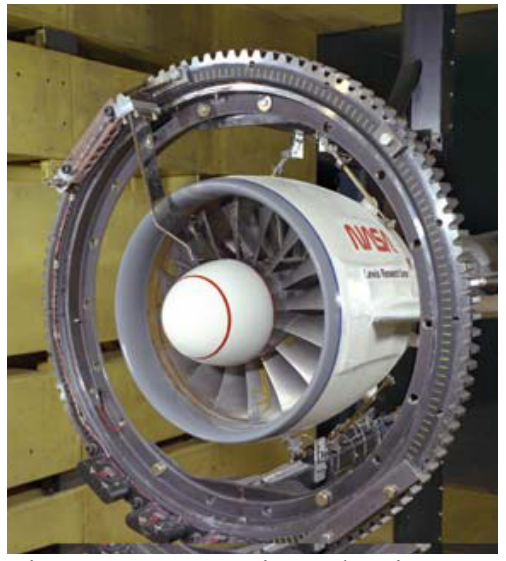

Figure 11.- Rotating rake ring assembly on geared advanced ducted propulsor in the 9 - by 15 -foot wind tunnel.

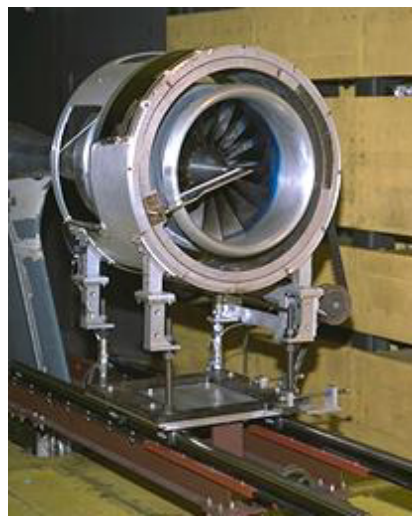

Figure 12.- Rotating rake drum assembly on 22 in. fan in the 9 - by 15 -foot wind tunnel. 
A Source Diagnostic Test (ref. 21) (SDT) was conducted in the 9- by 15 -foot wind tunnel using the 22 in. fan drive rig by NASA Glenn as part of the AST. This fan was a 22-bladed fan that had sonic tip speed at 100 percent $\mathrm{rpm}$. In one important phase of the test, the effect of stator sweep was investigated. The concept involved returning to a cut-on set of stators; sweep was introduced to mitigate the effect of cut-on BPF. The Rotating Rake measurements showed that compared to a standard cut-off set (26 vs. 54 Vanes), the swept vane set reduced the mode tone power significantly. This test also demonstrated the ability of the Rotating Rake to make valid mode measurements with the fan at sonic tip speed. Recall that at $M_{t i p}>1$, the $m=B$ mode cuts on. It was shown that in the inlet the rake wake contaminates the $m=B$ mode. By analyzing mode measurements taken at fan speeds below the rotor mode cut-on, the magnitude of the rake wake contamination was estimated. When the mode measurements were analyzed above sonic tip speed, then increase in $m=B$ mode PWL was greater than $10 \mathrm{~dB}$. The physical assumption is made that the rake wake contamination would increase only slightly with rpm, but the rotor mode increases significantly. Therefore, the $m=B$ mode measurements above sonic fan tip speed in the inlet are assumed to be valid.

The rotating rake was also used to evaluate the acoustic benefit to a forward swept fan (ref. 22), the Quiet High Speed Fan (QHSF), compared to a baseline fan representing the Honeywell TFE731-60 engine. Being a representative fan model, support struts were included in the exhaust duct, in addition to the stator vanes. This test also presented an extension of the Rotating Rake reduction methodology to the analysis Multiple Pure Tones (MPTs) or "buzz-saw" noise. MPTs occur at shaft orders below BPF with the interesting characteristic that the $m$-order generated at a given shaft order is numerically, the shaft order. The mode measurements showed that the QHSF was significantly quieter, but that the reduction was primarily from a lowering of the rotor-strut interaction tones rather than from a reduction in the MPTs that had been originally been the design goal. The Rotating Rake measurements suggested that the reduction mechanism may have been that the stator was shielding the strut from the wake of the rotor; though this is unconfirmed.

Follow up tests to the SDT, comparing different rotor sets; and the QHSF, measuring the effects of vane clocking, have been done, but not yet reported as of the date of this publication.

\section{TFE-731-60}

The most challenging and perhaps most significant application (ref. 23) was on a Honeywell full-scale turbofan engine, the TFE731-60. The TFE731-60 engine is currently certified on the Dassault Falcon 900EX. The TFE73120/40/60 engine family also powers the Lear 45, IAI Astra SPX, and the Dassault Falcon 50EX. This test was accomplished under the Advanced Subsonic Technology program sponsorship of the Engine Validation of Noise Reduction Concepts (EVNRC). The basic engine parameters are listed in table II. The schematic of the fan flowpath in figure 13 shows multiple sources of interaction modes. The engine was tested at the Honeywell engine test stand in San Tan, Arizona. Photographs of the inlet and exhaust duct rake assemblies with the engine on the test stand are shown in figure 14.

TABLE II.-TFE731-60 ENGINE PARAMETERS

\begin{tabular}{|c|c|}
\hline Basic Engine Weight & $988 \mathrm{lb}$ \\
\hline Takeoff, Sea Level, Static Thrust & $5000 \mathrm{lb}$ \\
\hline Airflow & $187 \mathrm{lb} / \mathrm{sec}$ \\
\hline Cruise Bypass Ratio & 3.9 \\
\hline Cycle Pressure Ratio & 22 \\
\hline Geared Fan Pressure Ratio & 1.70 \\
\hline
\end{tabular}

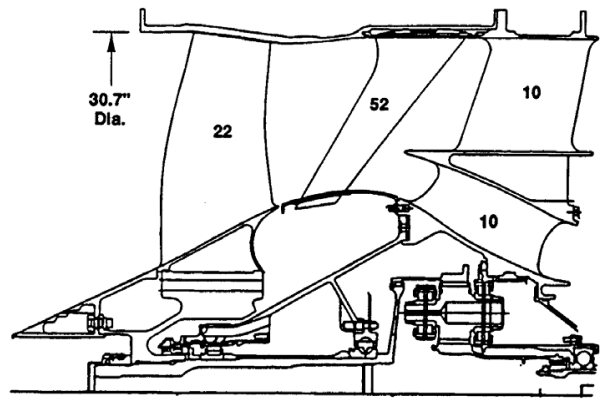

Figure 13.-TFE731 flow-path. 

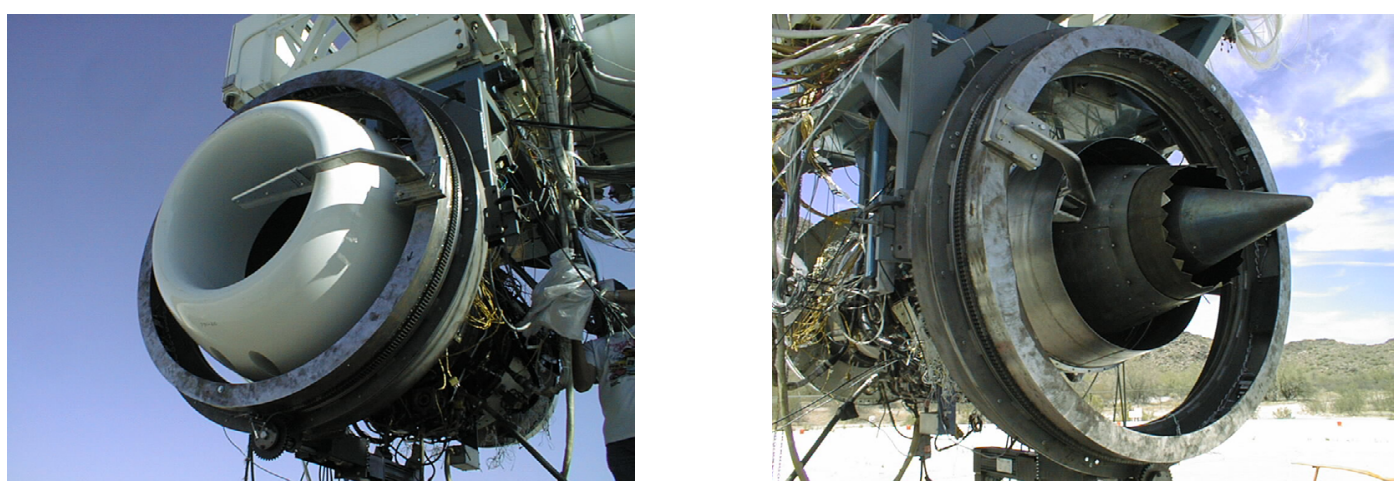

Figure 14.--Rotating rake assembly on Honeywell TFE731-60.

The rotor-strut interaction modes at BPF were identified as the dominant modes but were a minor contribution to overall PWL, due to the strength of the extraneous (background) modes. Rotor transmission losses were shown to result in lower co-rotating modes in the inlet compared to the exhaust. The 2BPF rotor-vane interaction mode was clearly identified in the inlet and exhaust, and observed to dominate. Repeatability of the measurements was shown to be excellent by comparing results from two separate test builds. An attempt to measure the rotor-locked noise was inconclusive due to the weakness of the rotor mode. The MPT sub-harmonics ("buzz-saw") were seen to be dominated by the shaft-orders just under $1 / 2 \mathrm{BPF}$.

\section{Future Extensions}

An evaluation of the Trailing Edge Blowing concept on the 22 in. Fan Drive Rig is underway in the NASA Glenn 9- by 15-Foot Wind Tunnel. Currently, a Rotating Rake system is being designed for a Honeywell Tech7000 Turbofan (for the NASA sponsored Engine Validation Noise Reduction Technologies (EVNERT) program. The rotating rake will be used to measure the full-scale version of the QHSF and to provide detailed design information for $\mathrm{H}-\mathrm{Q}$ tubes. The analysis technique is currently being extended to measure and reduce duct modes over treated wall sections. The method has already been verified for treated inlet ducts $(\sigma=0)$, and current testing for annular treated sections is underway. These results will be reported in a future paper. A significant need is to develop analysis techniques to properly measure duct modes in sheared flows.

\section{References}

1. Hubbard, H. Harvey, editor, Aeroacoustics of Flight Vehicles: Theory and Practice: Volume 1, NASA Reference Publication 1258, Vol. 1, WRDC Technical Report 90-3052.

2. Sofrin, T.G. "Aircraft Turbomachinery Noise: Fan Noise," Notes for Lectures 21 and 22 for the Course in the Fluid Dynamics in Turbomachinery at ASME/Iowa State University, sponsored by Pratt \& Whitney Aircraft Division/United Aircraft Corporation.

3. Moore, C.J., "Measurement of Radial and Circumferential Modes in Annular and Circular Ducts," Journal of Sound and Vibration," Vol. 62, No. 2, 1979.

4. Cicon, D.E., Sofrin, T.G., and Mathews. D.E., "Investigation of a Continuously Traversing Microphone System for Mode Measurement" NASA CR-168040, PWA-5846-26, November 1982.

5. Cicon, C.E. and Sofrin, T.G., "Method for Extracting Forward Acoustic Wave Components from Rotating Rake Measurements from Rotating Microphone Measurements in the Inlets of Turbofan Engines," NASA CR-195457, April 1995.

6. Meyer, H.D., Envia, E. “Aeroacoustic Analysis of Turbofan Noise Generation,” NASA CR-4715, March 1996.

7. Rice, E.J., Heidmann, M.F., and Sofrin, T.G., " Modal Propagation Angles in a Cylindrical Duct with Flow and Their Relation to Sound Radiation," AIAA 97-0183.

8. Tyler, J.M., and Sofrin, T.G., "Axial Flow Compressor Studies," SAE Transactions, Vol. 70, 1962.

9. Rice, E.J., "Optimum Wall Impedance for Spinming Modes-A Correlation with Mode Cut-off Ratio,” Journal of Aircraft, Vol. 16, No. 5. 
10. Hall, D.G., Bridges, J.E., and Heidelberg, L.J., “A Unique Ducted Fan Test Bed for Active Noise Control and Aeroacoustics Research," NASA TM-107213, AIAA-96-1740.

11. Sutliff, D.L, Nallasamy, M., Heidelberg, and L.J., Elliott, D.M., "Baseline Acoustic Levels of the NASA Active Noise Control Fan," NASA TM-107214, AIAA-96-1745.

12. Sutliff, D.L., Heidelberg, L.J., and Envia, E, “Coupling of Low Speed Fan Stator Vane Unsteady Pressures to Duct Modes: Measured vs. Predicted". AIAA-99-1864.

13. Nallasamy, M., Sutliff, D.L., and Heidelberg, L.J., "Propagation of Spinning Acoustic Modes in Turbofan in Turbofan Exhaust Ducts," Journal of Propulsion and Power, Vol. 16, No. 5, pp. 736-743.

14. Heidelberg, L.J., Sutliff, D.L., and Nallasamy, M., 'Azimuthal Directivity of Fan Tones Containing Multiple Modes," NASA TM-107464, AIAA-97-1587.

15. Lan, J.H., Premo, J.W., and Sutliff, D.L., "Inlet Mode Measurements with an Inflow Control Device Microphone Array," AIAA-2002-2563.

16. D. de la Riva, R. Burdisso and W. Ng, "Aft Fan Noise Control Using Herschel-Quincke/liner Systems” AIAA-2005-3071.

17. Sutliff, D.L., Tweedt, D.L., Fite, E.B., and Envia, E. "Low-Speed Fan Noise Reduction with Trailing Edge Blowing," International Journal of Aeroacoustics," Vol. 1, No. 3.

18. Heidelberg, L.J., and Hall, D.G., "Inlet Acoustic Mode Measurements Using a Continuously Rotating Rake," Journal of Aircraft, Vol. 32, No. 4.

19. Heidelberg, L.J. and Elliott, D.M., “A Comparison of Measured one Modes for Two Low Noise Propulsion Fans," NASA/TM-2000-210231, AIAA-2000-1989.

20. Parente, C.A., Acas, N, Walker, B.E., Hesh, A.S., and Rice, E.J., "Hybrid Active/Passive Jet Engine Noise Suppression System,"NASA/CR-1999-208875.

21. Heidelberg, L.J, "Fan Noise Source Diagnostic Test-Tone Modal Structure Results," NASA/TM-2002211954, AIAA-2002-2428.

22. Heidelberg, L.J, "Comparison of Tone Mode Measurements for a Forward Swept and Baseline Rotor Fan," AIAA-2003-3293.

23. Sutliff, D.L., Konno, K.E., and Heidelberg, L.J., "Duct Mode Measurements on the TFE731-60 Full Scale Engine," NASA/TM-2002-211573, AIAA-2002-2564. 



\section{Appendix}

This appendix outlines the derivations of the equations presented in the main body of the paper. General assumptions are uniform Mach number in a constant area cylindrical or annular duct.

\section{Symbols}

$\begin{array}{llll}\text { a,b } & \text { constants } & \mathrm{N} & \text { number of pulses per fan rev } \\ \mathrm{A} & \text { duct area } & \mathrm{n} & \text { radial mode order } \\ \mathrm{B} & \text { number of fan blades } & \mathrm{p} & \text { acoustic pressure } \\ \mathrm{C} & \text { normalizing coefficient } & \mathrm{P} & \text { modal pressure amplitude } \\ \mathrm{D} & \text { duct diameter } & \hat{\mathrm{P}} & \text { modal power amplitude } \\ \mathrm{E} & \text { duct profile function } & \mathrm{Q} & \text { weighting function } \\ \mathrm{f} & \text { frequency } & \mathrm{R} & \text { duct radius } \\ \mathrm{G} & \text { mode power Mach effect } & \mathrm{r} & \text { radial co-ordinate } \\ \mathrm{h} & \text { fan fundamental harmonic } & \mathrm{t} & \text { temporal co-ordinate } \\ \mathrm{J} & \text { Bessel function }-1 \text { st kind } & \mathrm{S} & \text { fan shaft harmonic } \\ \mathrm{k} & \text { wavenumber } & \mathrm{V} & \text { number of vanes } \\ \mathrm{M} & \text { Mach number } & \mathrm{X} & \text { axial co-ordinate } \\ \mathrm{m} & \text { circumferential mode order } & \mathrm{Y} & \text { Bessel function - 2nd kind }\end{array}$

\section{A. Solution to Wave Equation with Boundary Conditions Representative in Turbofans}

The non-dimensional form of the convective wave equation in cylindrical co-ordinates with axially uniform mean flow in a constant area duct is written (ref. 1) as:

$$
\begin{gathered}
\nabla^{2} p(r, \Theta, x, t)=\left(\frac{\partial}{\partial t}+M \frac{\partial}{\partial x}\right)^{2} p(r, \Theta, x, t) ; \\
\text { with the non-dimensionalizations } \quad M=\frac{u^{*}}{c_{0}^{*}} ; x=\frac{x^{*}}{R} ; r=\frac{r^{*}}{R} ; r=\frac{x^{*}}{R} ; t=\frac{t^{*}}{R / c_{0}^{*}} ; p=\frac{p^{*}}{\rho^{*} c_{0}^{* 2}} ; f=\frac{f^{*} R}{c_{0}^{*}}
\end{gathered}
$$

This form of the equation is known for it's separable solutions:

$$
p(\theta, r, x, t)=p * E(\kappa r) e^{i(2 \pi f t+m \theta \pm k x)}
$$

A cyclic temporal variation is superimposed upon the entire solution:

$$
P_{t}(t)=e^{i 2 \pi t}
$$

The form of the circumferential solution is deduced from the observation that the pressure must be single-valued azimuthally:

$$
P_{\theta}(\theta)=P_{\theta}(\theta+2 \pi) ; \text { results in } \quad P_{\theta}(\theta)=\cos (m \theta)
$$

The variable $m$ is defined as the circumferential mode order and indicates the number of pressure cycles in the circumferential direction. 
The solution in the axial direction, where $k$ is defined as the axial wave number, is given as:

$$
P_{x}(x)=e^{-i k_{x} x} ; \quad \frac{k_{x}}{\eta}=\frac{1}{\left(1-M^{2}\right)}\left[-M \pm \sqrt{1-\left(1-M^{2}\right)\left(\frac{\kappa}{\eta}\right)^{2}} ; \quad \eta=f R / c\right.
$$

Since the text clearly illustrated that the circumferential solution arises from the rotation of the rake inducing a Doppler-shift that separates the circumferential modes. The nature of the radial rake indicates that the primary interest is the radial solution. The form of the radial solution is the well-known Bessel's Equation:

$$
\frac{d^{2} P(r)}{d r^{2}}+\frac{1}{r} \frac{d P(r)}{d r}+\left\{\eta^{2}\left[\left(1-M \frac{k_{x}}{\eta}\right)^{2}-\left(\frac{k_{x}}{\eta}\right)^{2}\right]^{2}-\left(\frac{m^{2}}{r^{2}}\right)\right\} P(r)=0
$$

The solution to this ordinary differential Equation is an eigenvalue problem with an infinite number of solutions:

$$
P(r)=a J\left(\kappa_{n} r\right)+b Y\left(\kappa_{n} r\right) ; \quad a, b \text { arbitrary, } n=0,1,2, \ldots
$$

where $J$ and $Y$ are the Bessel's functions of the 1st and 2nd kind, of order $\mathrm{n}$. The index $n$ is the radial mode order, which physically indicates the number of pressure nodes in the radial profile. The pressure profile is a superposition of cirumferential and radial modes. Each term in this superposition contains a radial duct profile function written as:

$$
E_{m n}(r)=C_{m n} \Psi_{m n}(r)=C_{m n}\left[J_{m}\left(\kappa_{m n} r\right)+Q_{m n} Y_{m}\left(\kappa_{m n} r\right)\right] ; \quad n=0,1,2, \ldots
$$

with subscripts $m$ for the circumferential mode order, and $n$ for the radial mode order.

Since the Bessel functions can vary substantially in form, by convention $a=C, b=C^{*} Q$ is chosen where $C$ is a weighting factor related to the integration of $\Psi$ and $Q$ is termed as a second eigenvalue, though technically it is not. $\kappa$ is an eignevalue found without reference to $Q$ as shown in Eq. B.7 or Eq. B.8 solves the proper eigenfunction $P(r)$. $Q$ is from the boundary conditions and determines the proper radial shape of the eignefunction.

The general boundary conditions are determined from the relationship between the non-dimensional particle velocity and pressure at the duct walls:

$$
\eta^{2}\left(1-M \frac{k_{x}}{\eta}\right)^{2} \varepsilon=\frac{d p}{d r} ; \quad \frac{p}{i \eta \varepsilon_{N}}=\frac{Z}{\rho_{0}^{*} c_{0}^{*}}=\frac{1}{\hat{\mathrm{A}}}
$$

Where $\varepsilon$ is the particle displacment in the flow positive in the radial direction, and is the radial particle displacment at the wall, positive into the wall. When the boundary conditions are applied, this becomes:

$$
\frac{d P(1)}{d r}=-i \eta \hat{A}_{o w}\left(1-M \frac{k_{x}}{\eta}\right)^{2} P(1) ; \quad \frac{d P(\sigma)}{d r}=i \eta \hat{A}_{i w}\left(1-M \frac{k_{x}}{\eta}\right)^{2} P(\sigma)
$$

The boundary condition for the hardwall case is that the pressure be normal to the duct inner and outer wall (a consequence of the zero acoustic velocity at the wall). Or, for a hardwall duct the inner and outer wall admittances are 0 so Eq. A.10 reduces to:

$$
\frac{d P(1)}{d r}=\frac{d P(\sigma)}{d r}=0
$$




\section{B. Eigenvalue Solutions}

The solution of the eigenvalue problem is based on the general boundary conditions from the continuity of particle displacement at the wall (Eq. A.10) that are repeated here:

$$
\begin{aligned}
& \frac{d P(1)}{d r}=-i \eta \hat{A}_{o w}\left(1-M \frac{k_{x}}{\eta}\right)^{2} P(1) ; \quad \frac{d P(\sigma)}{d r}=i \eta \hat{A}_{i w}\left(1-M \frac{k_{x}}{\eta}\right)^{2} P(\sigma) \\
& \text { where: } \quad P_{m n}(r)=p_{m n} E_{m n}(r)=C_{m n} \Psi_{m n}(r)=C_{m n}\left[J_{m}\left(\kappa_{m n} r\right)+Q_{m n} Y_{m}\left(\kappa_{m n} r\right)\right]
\end{aligned}
$$

Taking the derivative of this equation with respect to $r$, and applying the recursive definition of the Bessel Function derivative $\left(m J_{m}\left(\kappa_{m n}\right)-\kappa_{m n} J_{m}^{\prime}\left(\kappa_{m n}\right)=\kappa_{m n} J_{m+1}\left(\kappa_{m n}\right)\right)$ results in:

$$
\begin{aligned}
\frac{d E_{m n}(r)}{d r} & =\frac{d C_{m n}\left[J_{m}\left(\kappa_{m n} r\right)+Q_{n m} Y_{m}\left(\kappa_{m n} r\right)\right]}{d r}=C_{m n} \kappa_{m n}\left[J_{m}^{\prime}\left(\kappa_{m n} r\right)+Q_{m n} Y_{m}^{\prime}\left(\kappa_{m n} r\right)\right] \\
& =C_{m n} \kappa_{m n}\left\{\left[\left(\frac{m}{\kappa_{m n} r}\right) J_{m}\left(\kappa_{m n} r\right)-J_{m+1}\left(\kappa_{m n} r\right)\right]+Q_{m n}\left[\left(\frac{m}{\kappa_{m n} r}\right) Y_{m}\left(\kappa_{m n} r\right)-Y_{m+1}\left(\kappa_{m n} r\right)\right]\right\}
\end{aligned}
$$

Substituting Eq. B.3 into the left side of Eq. B.1, and Eq. B.2 into the right side, canceling out the coefficient $C_{m n}$ results at the outer wall:

$$
\begin{gathered}
\kappa_{m n}\left\{\left[\left(\frac{m}{\kappa_{m n}}\right) J_{m}\left(\kappa_{m n}\right)-J_{m+1}\left(\kappa_{m n}\right)\right]+Q_{m n}\left[\left(\frac{m}{\kappa_{m n}}\right) Y_{m}\left(\kappa_{m n}\right)-Y_{m+1}\left(\kappa_{m n}\right)\right]\right\} \\
=-i \eta \hat{A}_{o w}\left(1-M \frac{k_{x}}{\eta}\right)^{2}\left[J_{m}\left(\kappa_{m n}\right)+Q_{m n} Y_{m}\left(\kappa_{m n}\right)\right]
\end{gathered}
$$

and at the inner wall:

$$
\begin{gathered}
\kappa_{m n}\left\{\left[\left(\frac{m}{\kappa_{m n} \sigma}\right) J_{m}\left(\kappa_{m n} \sigma\right)-J_{m+1}\left(\kappa_{m n} \sigma\right)\right]+Q_{m n}\left[\left(\frac{m}{\kappa_{m n} \sigma}\right) Y_{m}\left(\kappa_{m n} \sigma\right)-Y_{m+1}\left(\kappa_{m n} \sigma\right)\right]\right\} \\
=+i \eta \hat{A}_{i w}\left(1-M \frac{k_{x}}{\eta}\right)^{2}\left[J_{m}\left(\kappa_{m n} \sigma\right)+Q_{m n} Y_{m}\left(\kappa_{m n} \sigma\right)\right]
\end{gathered}
$$

Solving both Equations for $Q_{m n}$ and setting the result equal to one another yields:

$$
\frac{\left[m+i \eta \hat{A}_{o w}\left(1-M \frac{k_{x}}{\eta}\right)^{2}\right] J_{m}\left(\kappa_{m n}\right)-\kappa_{m n} J_{m+1}\left(\kappa_{m n}\right)}{\left[m+i \eta \hat{A}_{o w}\left(1-M \frac{k_{x}}{\eta}\right)^{2}\right] Y_{m}\left(\kappa_{m n}\right)-\kappa_{m n} Y_{m+1}\left(\kappa_{m n}\right)}=\frac{\left[\frac{m}{\sigma}-i \eta \hat{A}_{i w}\left(1-M \frac{k_{x}}{\eta}\right)^{2}\right] J_{m}\left(\kappa_{m n} \sigma\right)-\kappa_{m n} J_{m+1}\left(\kappa_{m n} \sigma\right)}{\left[\frac{m}{\sigma}-i \eta \hat{A}_{i w}\left(1-M \frac{k_{x}}{\eta}\right)^{2}\right] Y_{m}\left(\kappa_{m n} \sigma\right)-\kappa_{m n} Y_{m+1}\left(\kappa_{m n} \sigma\right)}
$$

This equation can be solved iteratively by a number of means to obtain $\kappa$, then substitute into Eq. B.4 or Eq. B.5 to obtain $Q$. For the hardwall boundary conditions the admitances, $\hat{A}_{i w}$ and $\hat{A}_{o w}$, in Eq. B.6 are set to zero:

$$
\frac{m J_{m}\left(\kappa_{m n}\right)-\kappa_{m n} J_{m+1}\left(\kappa_{m n}\right)}{m Y_{m}\left(\kappa_{m n}\right)-\kappa_{m n} Y_{m+1}\left(\kappa_{m n}\right)}=\frac{\frac{m}{\sigma} J_{m}\left(\kappa_{m n} \sigma\right)-\kappa_{m n} J_{m+1}\left(\kappa_{m n} \sigma\right)}{\frac{m}{\sigma} Y_{m}\left(\kappa_{m n} \sigma\right)-\kappa_{m n} Y_{m+1}\left(\kappa_{m n} \sigma\right)}
$$


The profile for a cylindrical duct $(\sigma=0)$ requires that the radial solution be finite at the centerline. To $Q=0$ to Thus the radial duct function, $E$, reduces to:

$$
P_{m n}(r)=C_{m n} E_{m n}(r)=C_{m n} J_{m}\left(\kappa_{m n} r\right)
$$

The cylindrical duct eigenvalue solutions for softwall boundary conditions are found by noting $\hat{A}_{i w}$ in Eq. B.1 and $Q_{m n}$ in Eq. B.4 are zero. This results in:

$$
\begin{aligned}
& \frac{d P(1)}{d r}=-i \eta \hat{A}_{o w}\left(1-M \frac{k_{x}}{\eta}\right)^{2} P(1) ; \quad \frac{d P(0)}{d r}=0 \\
& \kappa_{m n} \frac{J_{m+1}\left(\kappa_{m n}\right)}{J_{m}\left(\kappa_{m n}\right)}-m-i \eta \hat{A}_{o w}\left(1-M \frac{k_{x}}{\eta}\right)^{2}=0
\end{aligned}
$$

Finally, the eigenvalue equation for the cylidrical hardwall duct is found by setting $\hat{A}_{\text {ow }}$ in Eq. B.10 to zero:

$$
\kappa_{m n} \frac{J_{m+1}\left(\kappa_{m n}\right)}{J_{m}\left(\kappa_{m n}\right)}-m=0
$$

\section{Derivation of the Weighting Factor, $C_{m n}$}

Since the profile of the Bessel functions can vary significantly with order, it is desirable to normalize the duct profile by a physical constant in order that meaningful comparisons of the mode amplitude can be made. The weighting factor can take several forms based on the desired physical reasoning. One form chosen in early modal analysis (ref. 2) was acoustic intensity based normalization by setting the integration across the duct to unity.

$$
\text { intensity: } \quad \int_{A} p^{2} d A=1
$$

An alternative form is to normalize by relating to power. In order to match the methodology of standard CAA codes (ref. 3) the normalization chosen is power based so that:

$$
\text { power: } \quad \int_{A} p^{2} d A=A
$$

From the section A, the radial profile is given by :

$$
\Psi_{m n}(r)=J_{m}\left(\kappa_{m n} r\right)+Q_{m n} Y_{m}\left(\kappa_{m n} r\right) ; \quad n=0,1,2, \ldots
$$

integrating,

$$
\int_{0}^{2 \pi} \int_{\sigma}^{1} C_{m n}^{2} \Psi_{m n}^{2}\left(\kappa_{m n} r\right) r d r d \Theta=2 \pi\left(1-\sigma^{2}\right)
$$

$$
C_{m n}^{2} \int_{\sigma}^{1} \Psi_{m n}^{2}\left(\kappa_{m n} r\right) r d r=\left(1-\sigma^{2}\right)
$$

Under certain conditions the functions are orthogonal. The orthogonality property of the Bessel Function (ref. 4) is:

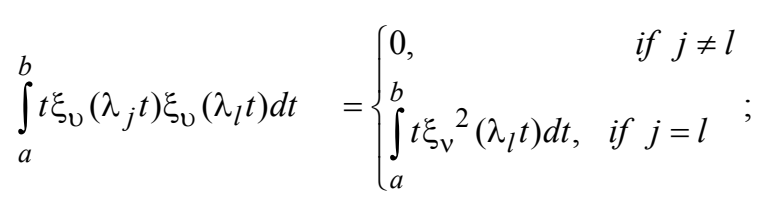

provided the following two conditions hold:

(1) $\lambda_{l}$ is a real zero of $h_{1} \lambda \xi_{v+1}(\lambda b)-h_{2} \xi_{v}(\lambda b)=0$

(2) there exisits $k_{1} \& k_{2} \neq 0$ such that $k_{1} \lambda_{l} \xi_{v+1}\left(\lambda_{l} a\right)-k_{2} \xi_{v}\left(\lambda_{l} a\right)=0$ 
Applying the hardwall boundary conditions from Eq. A.11 and the recursive definition of the Bessel function shows that (1) \& (2) are satisfied with the eigenvalues $\kappa$. Re-arranging the impedance boundary conditions Eq. A.10:

$$
\frac{d\left(E_{m n}\left(\kappa_{m n} r\right)\right)}{d r}=-i \hat{A}\left(1-M \frac{k_{x}}{\eta}\right)^{2} E_{m n}\left(\kappa_{m n} r\right) \rightarrow \kappa_{m n} E_{m n}^{\prime}\left(\kappa_{m n} r\right)+i \hat{A}\left(1-M \frac{k_{x}}{\eta}\right)^{2} E_{m n}\left(\kappa_{m n} r\right)=0
$$

At the outer wall $(b=1)$ this equation takes on the form of condition (1):

$$
\begin{gathered}
{\left[-\kappa_{m n} E_{m+1, n}\left(\kappa_{m n}\right)+m E_{m n}\left(\kappa_{m n}\right)\right]+i \hat{A}_{o w}\left(1-M \frac{k_{x}}{\eta}\right)^{2} E_{m n}\left(\kappa_{m n}\right)=0} \\
\kappa_{m n} E_{m+1, n}\left(\kappa_{m n}\right)-\left[m+i \hat{A}_{o w}\left(1-M \frac{k_{x}}{\eta}\right)^{2}\right] E_{m n}\left(\kappa_{m n}\right)=0
\end{gathered}
$$

Likewise, at the inner wall $(\mathrm{a}=\sigma)$ the boundary conditions take on the form of condition (2):

$$
\begin{gathered}
{\left[-\kappa_{m n} E_{m+1, n}\left(\kappa_{m n} \sigma\right)+\frac{m}{\sigma} E_{m n}\left(\kappa_{m n} \sigma\right)\right]-i \hat{A}_{i w}\left(1-M \frac{k_{x}}{\eta}\right)^{2} E_{m n}\left(\kappa_{m n} \sigma\right)=0} \\
-\kappa_{m n} E_{m+1, n}\left(\kappa_{m n} \sigma\right)+\left[\frac{m}{\sigma}-i \hat{A}_{i w}\left(1-M \frac{k_{x}}{\eta}\right)^{2}\right] E_{m n}\left(\kappa_{m n} \sigma\right)=0
\end{gathered}
$$

It is recognized that this is not strictly correct because for the general case the $\kappa_{\mathrm{mn}}$ is not a real eigenvalue, but may be complex. Nonetheless, the form of the solution will be used in order to be consistent in the normalization. Future work may investigate the derivation of a rigorously correct solution of the normalizing constant.

The general solution to the integral is then:

$$
\begin{array}{r}
\int_{\sigma}^{1} \Psi_{m}{ }^{2}\left(\kappa_{m n} r\right) r d r=\left.\frac{1}{2} r^{2}\left[\left(1-\frac{m^{2}}{\kappa_{m n}^{2} r^{2}}\right) \Psi_{m n}^{2}\left(\kappa_{m n} r\right)+\Psi_{m n}^{\prime 2}\left(\kappa_{m n} r\right)\right]\right|_{\sigma} ^{1} \mathrm{C} .9 \\
\frac{\left(1-\sigma^{2}\right)}{C_{m n}^{2}}=\frac{1}{2}\left[\left(1-\frac{m^{2}}{\kappa_{m n}^{2}}\right) \Psi_{m n}^{2}\left(\kappa_{m n}\right)+\Psi_{m n}^{\prime 2}\left(\kappa_{m n}\right)\right]-\frac{\sigma^{2}}{2}\left[\left(1-\frac{m^{2}}{\kappa_{m n}^{2} \sigma^{2}}\right) \Psi_{m n}^{2}\left(\kappa_{m n} \sigma\right)+\Psi_{m n}^{\prime 2}\left(\kappa_{m n} \sigma\right)\right]
\end{array}
$$

Applying the general annular duct, non-zero impedance boundary conditions:

$$
\begin{gathered}
\frac{d P(1)}{d r}=-i \eta \hat{A}_{o w}\left(1-M \frac{k_{x}}{\eta}\right) P(1) ; \frac{d P(\sigma)}{d r}=i \eta \hat{A}_{i w}\left(1-M \frac{k_{x}}{\eta}\right) P(\sigma) \\
\frac{d \Psi_{m}\left(\kappa_{m n} r\right)}{d r}=-i \eta \hat{A}\left(1-M \frac{k_{x}}{\eta}\right) \Psi_{m}\left(\kappa_{m n} r\right) \\
\kappa_{m n} \Psi_{m}^{\prime}\left(\kappa_{m n}\right)=-i \eta \hat{A}_{o w}\left(1-M \frac{k_{x}}{\eta}\right) \Psi_{m}\left(\kappa_{m n}\right) ; \quad \kappa_{m n} \Psi_{m}^{\prime}\left(\kappa_{m n} \sigma\right)=i \eta \hat{A}_{i w}\left(1-M \frac{k_{x}}{\eta}\right) \Psi_{m}\left(\kappa_{m n} \sigma\right) \\
\Psi_{m}^{\prime}\left(\kappa_{m n}\right)=-\frac{i \eta \hat{A}_{o w}}{\kappa_{m n}}\left(1-M \frac{k_{x}}{\eta}\right) \Psi_{m}\left(\kappa_{m n}\right) ; \quad \Psi_{m}^{\prime}\left(\kappa_{m n} \sigma\right)=\frac{i \eta \hat{A}_{i w}}{\kappa_{m n}}\left(1-M \frac{k_{x}}{\eta}\right) \Psi_{m}\left(\kappa_{m n} \sigma\right)
\end{gathered}
$$


Substituting the re-arranged boundary conditions equations into the definition of $C_{m n}$ derivative:

$$
\begin{array}{r}
\frac{1}{C_{m n}^{2}}=\frac{1}{2\left(1-\sigma^{2}\right)}\left\{\left[\left(1-\frac{m^{2}}{\kappa_{m n}^{2}}\right) \Psi_{m n}^{2}\left(\kappa_{m n}\right)-\left(\frac{\eta A_{o w}}{\kappa_{m n}}\right)^{2}\left(1-M \frac{k_{x}}{\eta}\right)^{2} \Psi_{m}^{2}\left(\kappa_{m n}\right)\right]\right. \\
\left.-\left[\left(\sigma^{2}-\frac{m^{2}}{\kappa_{m n}^{2}}\right) \Psi_{m n}^{2}\left(\kappa_{m n} \sigma\right)-\sigma^{2}\left(\frac{\eta A_{i w}}{\kappa_{m n}}\right)^{2}\left(1-M \frac{k_{x}}{\eta}\right)^{2} \Psi_{m}{ }^{2}\left(\kappa_{m n} \sigma\right)\right]\right\}
\end{array}
$$

For the hardwall condition $A=0$; the definition of $C_{m n}$ reduces to:

$$
\frac{1}{C_{m n}^{2}}=\frac{1}{2\left(1-\sigma^{2}\right)}\left\lfloor\left(1-\frac{m^{2}}{\kappa_{m n}^{2}}\right) \Psi_{m n}^{2}\left(\kappa_{m n}\right)-\left(\sigma^{2}-\frac{m^{2}}{\kappa_{m n}^{2}}\right) \Psi_{m n}^{2}\left(\kappa_{m n} \sigma\right)\right\rfloor
$$

For a cylindrical duct, equation C.15 simplifies to (impedance condition):

$$
\begin{aligned}
& \text { with } \sigma=0 ; \quad \Psi_{m n}\left(\kappa_{m n}\right)=J_{m}\left(\kappa_{m n}\right) ; \Psi_{m n}(0)=J_{m}(0)=0 ; \quad m \neq 0 \\
& \frac{1}{C_{m n}^{2}}=\frac{1}{2}\left[\left(1-\frac{m^{2}}{\kappa_{m n}^{2}}\right) J_{m n}^{2}\left(\kappa_{m n}\right)-\left(\frac{\eta \hat{A}_{o w}}{\kappa_{m n}}\right)^{2}\left(1-M \frac{k_{x}}{\eta}\right)^{2} J_{m}^{2}\left(\kappa_{m n}\right)\right]
\end{aligned}
$$

and for the hardwall condition, this further simplifies to: $\quad \frac{1}{C_{m n}^{2}}=\frac{1}{2}\left(1-\frac{m^{2}}{\kappa_{m n}^{2}}\right) J_{m}{ }^{2}\left(\kappa_{m n}\right)$

\section{Doppler-Shift of Duct Modes in Rotating Reference Frame}

The pressure at a fixed radial and axial location in the duct from all modes is: $p(\Theta, t)=\sum_{s=1}^{\infty} \sum_{m=-M}^{m=+M} A_{m}^{s} e^{-i(s \omega t-m \theta)}$

If the location is slowly rotating in the circumferential direction: $\Theta=\Omega t ; \quad p(\Theta, t)=\sum_{s=1}^{\infty} \sum_{m=-M}^{m=+M} A_{m}^{s} e^{-i(s \omega-m \Omega) t}$

For a typical application the rake rotates at a fraction of the fan speed: $\Omega=\frac{1}{v} \omega ; s=B$

Substituting Eq. D.3 into Eq. D.2 it is seen that the cyclical part becomes:

$$
(s \omega-m \Omega)=(B \omega-m(\omega / v))=\omega(B-(m / v))
$$

The mode frequency is then:

$$
f_{m}=\omega(B-(\mathrm{m} / \mathrm{v}))
$$


Thus the frequency is shifted from the fundamental by an amount proportional to the mode number, and inversely proportional to the speed ratio. Note that for a rake that rotates in the same direction as the rotor, co-rotating modes $(+m)$ will be reduced in frequency and counter-rotating modes $(-m)$ will be shifted higher in frequency. The plane wave $(m=0)$ is at the fan harmonic.

\section{E. Non-Interference of Rake Wake}

The wake of the rake is ingested by the rotor and contaminates the acoustic field. Fortunately, due to the rotating frame of reference all of the contamination occurs at a single Doppler-shifted frequency. A physical explanation was given in the text; here is the analytical proof:

The pressure due to a fixed distortion: $\quad p(\Theta, t)=A_{m}^{s} e^{-i(s \omega t-(s \pm l) \theta)}$

If this distortion is slowly rotating: $\quad p(\Theta, t)=A_{m}^{s} e^{-i[s(\omega \pm l \Omega) t-(s \pm l) \theta]}$

The cyclical portion is: $\quad(s \omega \pm l \Omega) t-(s \pm l) \theta=(s \omega \pm l \Omega) t-(s \pm l) \Omega t=s \omega t \pm l \Omega t-s \Omega t \mp l \Omega t=s(\omega-\Omega) t \quad \mathrm{E} .3$

so the frequency (with $s=B)$ is: $\quad f_{\text {rake }}=s(\omega-\Omega)=\omega s(1-\Omega / \omega)=\omega B(1-1 / v)$

from the previous section note that for $m=B: f_{m=B}=\omega(B-(m / v))=\omega B(1-(1 / v))$

In an unpublished letter, dated 20 November 1981, (this was to be an appendix to an earlier report (ref. 5), Sofrin demonstrated the non-interference this way (original text and notation):

"Consider a single mode generated by the rotor cutting the wake of a radial probe positioned at $\theta=0$ :

$$
p_{m n}(0 ; \theta, t)=\operatorname{Re} A_{m n} \exp i(m \theta-n B \Omega t)
$$

If the wake is moved to $\theta=\beta$, then the pressure at $(\theta+\beta)$ and time $(t+\beta / \Omega)$ will be the same as given by (1), or

$$
p_{m n}(\beta ; \theta+\beta, t+\beta / \Omega)=p_{m n}(0 ; \theta, t)
$$

Consequently, the pressure at $\theta$ and the to the wake at $\theta=\beta$ is

$$
p_{m n}(\beta ; \theta, t)=p_{m n}(0 ; \theta-\beta, t-\beta / \Omega)=\operatorname{Re} A_{m n} \exp i[m(\theta-\beta)-n B \Omega(t-\beta / \Omega)]
$$

The complete pressure, due to all modes and frequencies is then

$$
\left.p_{m n}(\beta ; \theta, t)=\sum_{m, n} p(\beta ; \theta, t)=\operatorname{Re} \sum_{m, n} A_{m n} \exp i[m(\theta-\beta)-n B \Omega t+n B \beta)\right]
$$

But the microphone senses the pressure only at the position $\theta=\beta$, (or $\theta=\beta+$ const) so the microphone signal $p_{\text {mic }}$ is:

$$
p_{m i c}=p_{m n}(\beta ; \beta, t)=\operatorname{Re} \sum_{m, n} A_{m n} \exp i[n B \beta-n B \Omega t]
$$


Since the exponential does not depend on $\mathrm{m}$, this can be written

$$
\begin{aligned}
& p_{\text {mic }}=\operatorname{Re} \sum_{n=1}^{\infty}\left(\sum_{-\infty}^{\infty} A_{m n}\right) \exp i(n B \beta-n B \Omega t) \\
& \text { or, with } \sum_{-\infty}^{\infty} A_{m n}=A_{n}, \\
& p_{m i c}=\operatorname{Re} \sum_{n=1}^{\infty} A_{n} \exp i n B(\beta-\Omega t)
\end{aligned}
$$

From Eq. (6) it is seen that the microphone signal, at any frequency $n B \Omega$ behaves exactly as if it were sensing the direct rotor field which has $n B$ lobes, spinning at $\Omega$. This signal will undergo a $2 \pi$ phase shift when the probe angle $\beta$ changes by $2 \pi / \beta$.

It should now become clear on reflection that no matter how complicated the wake-generated acoustic field, that after the probe has turned through 1 blade gap, the pressure sensed by the microphone is indistinguishable in amplitude and phase from its initial state, thus providing intuitive support to the analytical results."

\section{F. Least Squares Fit}

The modal solution is a least-squares curve fit to the measured pressure using the analytical radial pressure profile solutions as the basis functions. If the pressure has been separated by frequency and circumferential mode order, the pressure for at given radial and axial location is then:

$$
\begin{aligned}
p_{m r f} & =\sum_{n=0}^{\infty} p_{m n f} E_{m n f}\left(\kappa_{m n f} r\right) \\
p_{m r f} & =\sum_{n=0}^{N \max } p_{m n f} E_{m n f}\left(\kappa_{m n f} r\right)
\end{aligned}
$$

The difference between the measured and calculated pressure: $\delta=\sum_{n=0}^{N \max } p_{m n f} E_{m n f}\left(\kappa_{m n f} r\right)-p_{m r f}$

A weighting function is introduced to allow for weighting of errors based on area or other physical means. (In practice the weighting function $W_{i}$ has the effect of bad coding a microphone by setting $W_{i}=0$ for a suspicious channel, 1 for all others.)

$$
\begin{aligned}
\delta_{i} & =W_{i}\left[\sum_{n=0}^{N \max } p_{m n f} E_{m n f}\left(\kappa_{m n f} r_{i}\right)-p_{m r_{i} f}\right] \\
\text { The square of the error is: } & \delta_{i}^{2}=\left\{W_{i}\left[\sum_{n=0}^{N \max } p_{m n f} E_{m n f}\left(\kappa_{m n f} r_{i}\right)-p_{m r_{i} f}\right]\right\}^{2} \\
\text { Summing over the number of points } p: & \delta^{2}=\sum_{i=1}^{N_{p}} \delta_{i}^{2}=\sum_{i=1}^{N_{p}}\left\{W_{i}\left[\sum_{n=0}^{N \max } p_{m n f} E_{m n f}\left(\kappa_{m n f} r_{i}\right)-p_{m r_{i} f}\right]\right\}^{2}
\end{aligned}
$$


The concept of least-square method is to minimize the error squared, by taking the differential with respect to each $P_{m n f}$ and setting the result to zero. Which taking the series terms out of the summation and extending to the radial modes:

$$
\begin{aligned}
& \frac{\partial \delta^{2}}{\partial p_{m n_{1} f}}=2 \sum_{i=1}^{N p} W_{i}^{2}\left(E_{m n_{1} f}\left(\kappa_{m n_{1} f} r_{i}\right)\right)\left[\sum_{n=0}^{N \max }\left(p_{m n f} E_{m n f}\left(\kappa_{m n f} r_{i}\right)-p_{m r_{i} f}\right)\right], \\
& \frac{\partial \delta^{2}}{\partial p_{m n_{2} f}}=2 \sum_{i=1}^{N p} W_{i}^{2}\left(E_{m n_{2} f}\left(\kappa_{m n_{2} f} r_{i}\right)\right)\left[\sum_{n=0}^{N \max }\left(p_{m n f} E_{m n f}\left(\kappa_{m n f} r_{i}\right)-p_{m r_{i} f}\right)\right], \\
& \ldots
\end{aligned}
$$

Setting the derivative to zero and splitting the summation:

$$
\begin{aligned}
& 0=\sum_{i=1}^{N p} W_{i}^{2}\left(E_{m v f}\left(\kappa_{m v f} r_{i}\right)\right) \sum_{n=0}^{N \max } p_{m n f} E_{m v f}\left(\kappa_{m n f} r_{i}\right)-\sum_{i=1}^{N p} W_{i}^{2}\left(E_{m v f}\left(\kappa_{m v f} r_{i}\right)\right)\left(p_{m r_{i} f}\right) \\
& \sum_{n=0}^{N \max } p_{m n f} \sum_{i=1}^{N p} W_{i}^{2} E_{m v f}\left(\kappa_{m v f} r_{i}\right) E_{m n f}\left(\kappa_{m n f} r_{i}\right)=\sum_{i=1}^{N p} W_{i}^{2}\left(E_{m v f}\left(\kappa_{m v f} r_{i}\right)\right)\left(p_{m r_{i} f}\right)
\end{aligned}
$$

Which can be written in matrix form for a fixed frequency:

$$
\left[F_{v n}\right]\left[P_{n}\right]=\left[E_{v r}\right]\left[P_{r}\right] \quad\left[P_{n}\right]=\left[F_{v n}\right]^{-1}\left[E_{v r}\right]\left[P_{r}\right]
$$

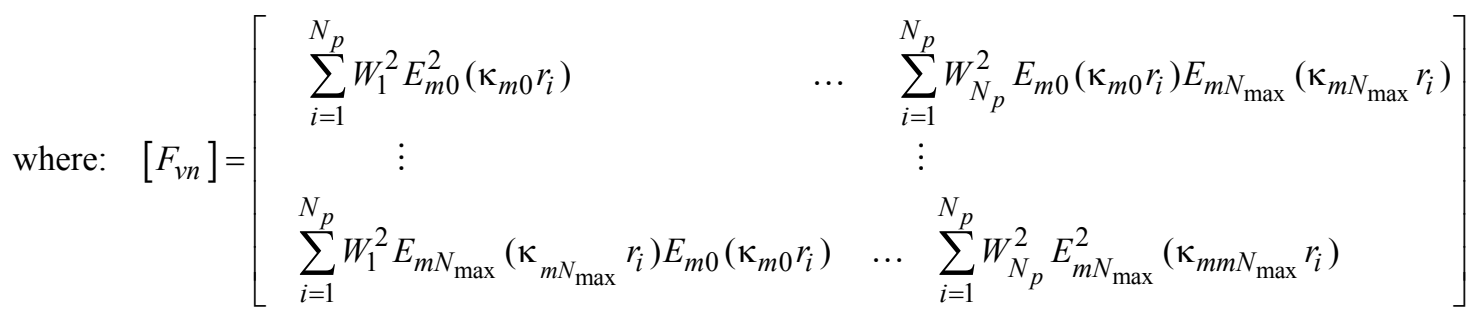

$$
\left[E_{v r}\right]=\left[\begin{array}{ccl}
W_{1}^{2} E_{m 0}\left(\kappa_{m 0} r_{1}\right) & \ldots & W_{N p}^{2} E_{m 0}\left(\kappa_{m 0} r_{N p}\right) \\
\vdots & & \vdots \\
W_{1}^{2} E_{m N_{\text {max }}}\left(\kappa_{m N_{\max }} r_{1}\right) & \ldots & W_{N p}^{2} E_{m N_{\max }}\left(\kappa_{m N_{\max }} r_{N p}\right)
\end{array}\right]
$$

measured pressures: $\left[P_{r}\right] \quad$ modal amplitudes (solution): $\left[P_{n}\right]$ note that the matrix Equation dimensions are: $\left[\mathrm{N}_{\max }\right] \sim\left[\mathrm{N}_{\max }, \mathrm{N}_{\max }\right]\left[\mathrm{N}_{\text {max }}, \mathrm{N}_{\text {meas }}\right]\left[\mathrm{N}_{\text {meas }} \mathrm{x} 1\right]$ 


\section{G. Derivation of Power}

The basic definition of power is the integration of the acoustic flux across a radial plane of the duct:

$$
\hat{\mathrm{P}}=\int_{A}\left\langle I_{x}\right\rangle d A
$$

For uniform axial flow it is straight-forward to show (* represents the complex conjugate.):

$$
I_{x}=\left(\frac{p}{\rho_{0}}+U u\right)\left(\rho_{0} u+\rho U\right) ; \quad p=c_{0}^{2} \rho ; M=U / c_{0} \rightarrow I_{x}=\left(1+M^{2}\right) p u^{*}+\frac{M}{\rho_{0} c_{0}} p p^{*}+\rho_{0} c_{0} M u u^{*}
$$

Inserting Eq. G.2 into Eq. G.1 results in:

$$
\begin{gathered}
\hat{P}_{m n s}=\int_{0}^{2 \pi} \int_{\sigma}^{1}\left\langle I_{a x}\right\rangle r d r d \theta=\frac{\pi R^{2}\left(1-\sigma^{2}\right)}{\rho_{o} U} \sum_{m=-\infty}^{\infty} \sum_{n=1}^{\infty} \sum_{s=-\infty}^{\infty} G_{m n s}\left|P_{m n s}\right|^{2} \\
\text { where } G_{m n s}=\left[M^{2}-\left(1+M^{2}\right) \Lambda_{m n s}^{*}+\left|\Lambda_{m n s}\right|^{2}\right] \\
\text { and } \Lambda_{m n s}=\frac{\gamma_{m n s}}{\frac{s B \Omega}{U}+\gamma_{m n s}} ; \gamma_{m n s}=\sqrt{\left(\frac{s B \Omega}{c_{0}}\right)^{2}-\beta^{2} \kappa_{m n}^{2}}
\end{gathered}
$$

The derivation of this is shown in detail in reference 3. It is recognized that some error is introduced since the above result relies on orthogonality to eliminate cross terms. Summation of the $+/-$ terms yields:

$$
\begin{gathered}
G_{m n s}=M^{2}-\left(1+M^{2}\right) \Lambda_{m n s}^{*}+\Lambda_{m n s} \Lambda_{m n s m n s}^{*} \\
G_{-m n(-s)}=M^{2}-\left(1+M^{2}\right) \Lambda_{-m n(-s)}^{*}+\Lambda_{-m n(-s)} \Lambda_{-m n(-s)}^{*} \\
\Lambda_{-m n(-s)}=\Lambda_{m n s}^{*} \\
G_{m n(-s)}=M^{2}-\left(1+M^{2}\right)\left(\Lambda_{m n s}^{*}\right)^{*}+\Lambda_{m n s}^{*}\left(\Lambda_{m n s}^{*}\right)^{*} \\
G_{m n s}+G_{-m n(-s)}=2 M^{2}-\left(1+M^{2}\right)\left(\Lambda_{m n s}^{*}+\Lambda_{m n s}\right)+2 \Lambda_{m n s} \Lambda_{m n s}^{*}
\end{gathered}
$$

Substituting the expression for $\Lambda_{m n s}$ into Eq. G.5, after manipulation:

$$
G_{m n s}=\operatorname{Re}\left\{\frac{\mp M^{2} \beta^{4}(s B \Omega / U) k_{m n s}}{\left(s B \Omega / c_{o} \pm M k_{m n s}\right)^{2}}\right\}
$$

Traditionally, this has been reduced assuming either pure real or pure imaginary eigenvalues to the form:

$$
G_{m n s}=\frac{\mp M^{2} \beta^{4}(s B \Omega / U) k_{m n s}}{\left(s B \Omega / c_{o} \pm M k_{m n s}\right)^{2}} ; \text { for a real eigenvalue } \quad G_{m n s}=0 ; \text { for an imaginary eigenvalue. } \quad \text { G.5 }
$$

A slightly different form will arise if the assumption that complex eigenvalues can occur: 


$$
G_{m n s}=\frac{M^{2} \beta^{4} \operatorname{Re}\left\{\frac{\omega}{U}\left(\mp k_{m n s}\right)\right\}}{\left|\frac{\omega}{c_{0}} \pm M k_{m n s}\right|^{2}}
$$

The final version for the rotating rake data analysis is:

$$
\overline{\mathrm{P}}=\mp \frac{\pi R^{2}\left(1-\sigma^{2}\right)}{\rho_{0} c_{0}}|\beta|^{4} R E\left\{\frac{\sqrt{1-\frac{1}{\zeta^{2}}}}{\left|1 \pm M_{D} \sqrt{1-\frac{1}{\zeta^{2}}}\right|^{2}}\right\}|P|^{2}
$$

\section{F. Comment}

Derivation of the equations unique to the Rotating Rake system have been presented as used for several applications. The data reduction based on these equations has been validated by experience and comparison to other methodologies. In order to keep the solutions manageable a significant simplification assumption was made, that the orthogonality solutions for various integrals applies. For certain boundary conditions (namely flow in treated ducts) this is not rigorously correct, as it assumes product terms involving non-identical modes due not contribute.

However, this assumption provides a solution that can be meaningfully analyzed. Future extensions of this analysis should include the solution complete with cross terms that were not included herein.

\section{G. References}

1. Hubbard, H. Harvey, editor, Aeroacoustics of Flight Vehicles: Theory and Practice: Volume 1, NASA Reference Publication 1258, Vol. 1, WRDC Technical Report 90-3052.

2. Moore, C.J., "Measurement of Radial and Circumferential Modes in Annular and Circular Ducts," Journal of Sound and Vibration," Vol. 62, No. 2, 1979.

3. Meyer, H.D., Envia, E. "Aeroacoustic Analysis of Turbofan Noise Generation," NASA CR-4715, March 1996.

4. Ambramowitz, M., and Stegun, I.A., Handbook of Mathematical Functions, National Bureau of Standards Applied Mathmatics Series, No. 55, U.S. Government Printing Office, Washington, DC, 1964.

5. Cicon, D.E., Sofrin, T.G., and Mathews. D.E., "Investigation of a Continuously Traversing Microphone System for Mode Measurement" NASA CR-168040, PWA-5846-26, November 1982 


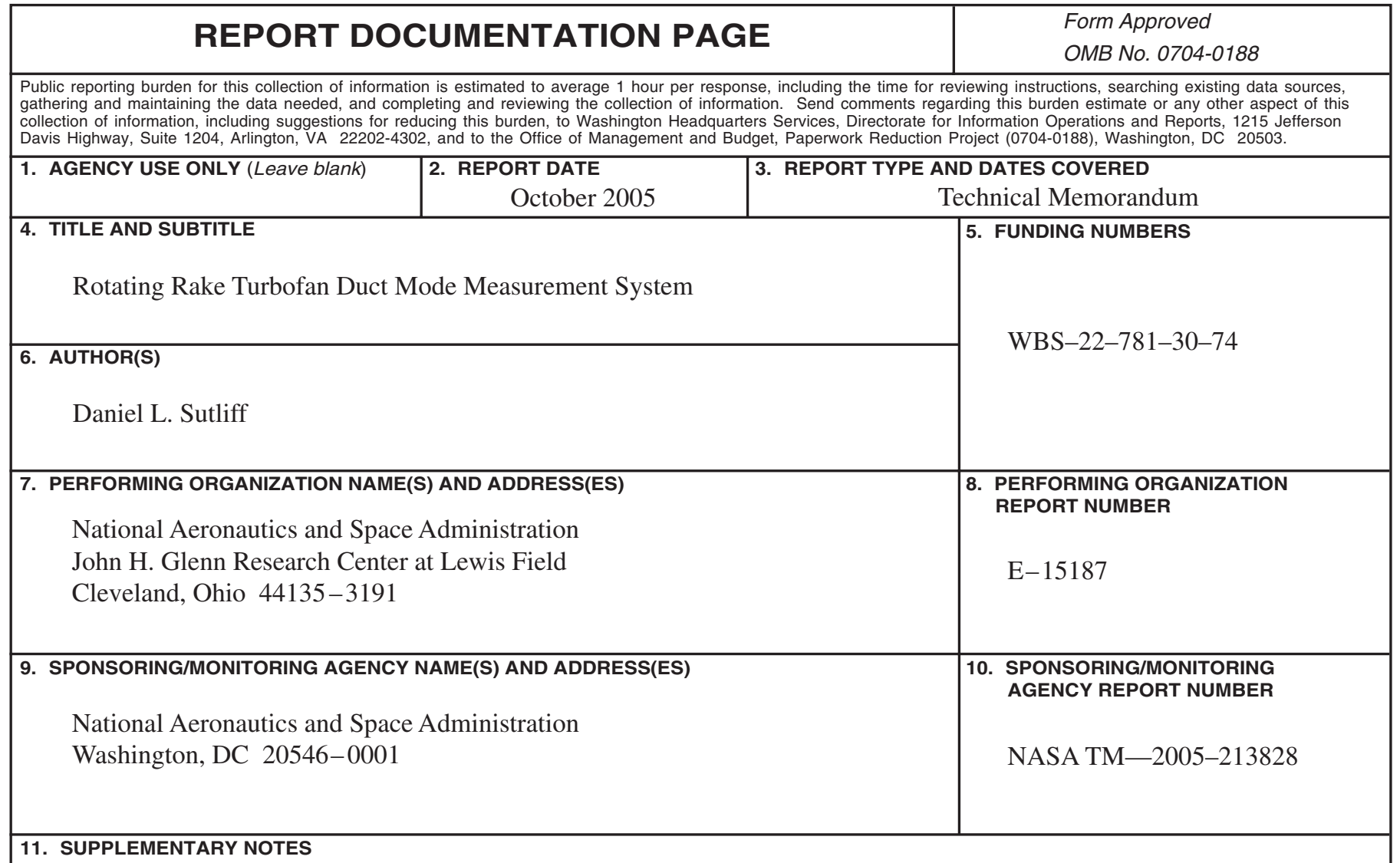

Prepared for NOISE-CON 2005 sponsored by the Institute of Noise Control Engineering, Minneapolis, Minnesota, October 17-19, 2005. Responsible person, Daniel L. Sutliff, e-mail: Daniel.L.Sutliff@ nasa.gov, organization code RTA, 216-433-6290.

\begin{tabular}{|l|l|}
\hline 12a. DISTRIBUTION/AVAILABILITY STATEMENT & 12b. DISTRIBUTION CODE
\end{tabular}

Unclassified - Unlimited

Subject Categories: 07 and 71

Available electronically at http://gltrs.grc.nasa.gov

This publication is available from the NASA Center for AeroSpace Information, 301-621-0390.

\section{ABSTRACT (Maximum 200 words)}

An experimental measurement system was developed and implemented by the NASA Glenn Research Center in the 1990s to measure turbofan duct acoustic modes. The system is a continuously rotating radial microphone rake that is inserted into the duct. This Rotating Rake provides a complete map of the acoustic duct modes present in a ducted fan and has been used on a variety of test articles: from a low-speed, concept test rig, to a full-scale production turbofan engine. The Rotating Rake has been critical in developing and evaluating a number of noise reduction concepts as well as providing experimental databases for verification of several aero-acoustic codes. More detailed derivation of the unique Rotating Rake equations are presented in the appendix.

\begin{tabular}{|c|c|c|}
\hline \multicolumn{3}{|c|}{$\begin{array}{l}\text { 14. SUBJECT TERMS } \\
\text { Turbofan; Duct modes; Aeroacoustics }\end{array}$} \\
\hline $\begin{array}{l}\text { 17. SECURITY CLASSIFICATION } \\
\text { OF REPORT } \\
\text { Unclassified }\end{array}$ & $\begin{array}{l}\text { 18. SECURITY CLASSIFICATION } \\
\text { OF THIS PAGE } \\
\text { Unclassified }\end{array}$ & $\begin{array}{l}\text { 19. SECURITY CLASSIFICATION } \\
\text { OF ABSTRACT } \\
\text { Unclassified }\end{array}$ \\
\hline
\end{tabular}



